\title{
Comparison of the Direct and Indirect Effects of Epinephrine on Hepatic Glucose Production
}

\author{
Chang An Chu, Dana K. Sindelar, Doss W. Neal, Eric J. Allen, E. Patrick Donahue, and Alan D. Cherrington \\ Department of Molecular Physiology and Biophysics, Vanderbilt University School of Medicine, Nashville, Tennessee 37232-0615
}

\begin{abstract}
To determine the extent to which the effect of a physiologic increment in epinephrine (EPI) on glucose production (GP) arises indirectly from its action on peripheral tissues (muscle and adipose tissue), epinephrine was infused intraportally (EPI po) or peripherally (EPI pe) into 18-h-fasted conscious dogs maintained on a pancreatic clamp. Arterial EPI levels in EPI po and EPI pe groups rose from $97 \pm 29$ to $107 \pm 37$ and $42 \pm 12$ to $1,064 \pm 144 \mathrm{pg} / \mathrm{ml}$, respectively. Hepatic sinusoidal EPI levels in EPI po and EPI pe were indistinguishable ( $561 \pm 84$ and $568 \pm 75 \mathrm{pg} / \mathrm{ml}$, respectively). During peripheral epinephrine infusion, GP increased from $2.2 \pm$ 0.1 to $5.1 \pm 0.2 \mathrm{mg} / \mathrm{kg} \cdot \mathrm{min}(10 \mathrm{~min})$. In the presence of the same rise in sinusoidal EPI, but with no rise in arterial EPI (during portal EPI infusion), GP increased from $2.1 \pm 0.1$ to $3.8 \pm 0.6 \mathrm{mg} / \mathrm{kg} \cdot \mathrm{min}$. Peripheral EPI infusion increased the maximal gluconeogenic rate from $0.7 \pm 0.4$ to $1.8 \pm 0.5 \mathrm{mg} /$ kg.min. Portal EPI infusion did not change the maximal gluconeogenic rate. The estimated initial increase in glycogenolysis was $\approx 1.7$ and $2.3 \mathrm{mg} / \mathrm{kg} \cdot \mathrm{min}$ in the EPI pe and EPI po groups, respectively. Gluconeogenesis was responsible for $60 \%$ of the overall increase in glucose production stimulated by the increase in plasma epinephrine (EPI pe). Elevation of sinusoidal EPI per se had no direct gluconeogenic effect on the liver, thus its effect on glucose production was solely attributable to an increase in glycogenolysis. Lastly, the gluconeogenic effects of EPI markedly decreased $(60-80 \%)$ its overall glycogenolytic action on the liver. ( $J$. Clin. Invest. 1997. 99:1044-1056.) Key words: epinephrine • gluconeogenesis • glycogenolysis
\end{abstract}

\section{Introduction}

It is well known that epinephrine plays an important role in the regulation of lipid, protein, and carbohydrate metabolism. During physiological and stressful conditions (i.e., hypoglycemia) an increase in circulating epinephrine stimulates adipose

Part of this work was presented at the 56th Annual Meeting of the American Diabetes Association, San Francisco, CA in June 1996.

Address correspondence to Chang An Chu, M.D., Department of Molecular Physiology and Biophysics, 702 Light Hall, Vanderbilt University School of Medicine, Nashville, TN 37232-0615. Phone: 615-322-7014; FAX: 615-322-7236; E-mail: Chang.An.Chu@MCmail. Vanderbilt.edu

Received for publication 15 October 1996 and accepted in revised form 16 December 1996.

J. Clin. Invest.

(C) The American Society for Clinical Investigation, Inc. 0021-9738/97/03/1044/13 \$2.00

Volume 99, Number 5, March 1997, 1044-1056 tissue lipolysis, muscle glycogenolysis, and hepatic glucose production. The stimulatory effect of epinephrine on hepatic glucose production arises from both an indirect action on extrahepatic tissues (muscle and adipose tissue) and a direct effect on the liver. The former represents the catecholamines' gluconeogenic effect, while the latter reflects its glycogenolytic action. Previous studies by Sacca et al. (1), Miles et al. (2), and Clutter et al. (3) suggested that increases in circulating epinephrine can stimulate gluconeogenesis in the human by mobilizing alanine and lactate from muscle and glycerol from adipose tissue. Stevenson et al. (4) and Steiner et al. (5) showed in dogs that epinephrine did indeed increase the uptake of alanine, lactate, and glycerol by the liver and that these changes were secondary to the effects of catecholamine on muscle and adipose tissue. In addition, we showed recently (6) that the direct effects of epinephrine and norepinephrine on the liver result solely from their stimulation of glycogenolysis.

Over the years, it has become obvious that hepatic glycogenolysis and gluconeogenesis tend to change reciprocally (1, $7-11)$. Previous in vivo studies $(4,6,7)$ showed that the initial increases in glucose production caused by increments in either plasma epinephrine or glucagon are primarily attributable to hepatic glycogenolysis. The glycogenolytic effect of either hormone quickly wanes, and with time gluconeogenesis is increased. Furthermore, studies in humans $(8,9)$ and animals $(10,11)$ have shown that increasing the gluconeogenic precursor (lactate or alanine or glycerol) load to the liver increases gluconeogenesis but does not change total glucose production. This suggests that the increase in gluconeogenesis is associated with a decrease in glycogenolysis. Since it has been demonstrated that the direct and indirect effects of epinephrine on hepatic glucose production induce a glycogenolytic and gluconeogenic (i.e., increasing gluconeogenic precursor loading) stimulation, respectively, it is of interest to determine whether the gluconeogenic effects of epinephrine limit its hepatic glycogenolytic effect.

The first aim of this study, therefore, was to determine whether long-term (3-h) elevation of portal epinephrine would stimulate gluconeogenesis within the liver. The second aim was to determine how much of the stimulatory action of epinephrine on hepatic glucose production arises from its direct glycogenolytic effect on the liver versus its peripheral effects on muscle and adipose tissue (i.e., supply of gluconeogenic precursors reaching the liver). The third aim was to determine the impact of the extrahepatic (gluconeogenic) effects of epinephrine on its glycogenolytic action in the liver.

\section{Methods}

Experiments were carried out on 1818 -h-fasted conscious mongrel dogs (20-26 kg) of either sex that had been fed a standard diet of meat and chow (31\% protein, $52 \%$ carbohydrate, $11 \%$ fat, and $6 \%$ fiber based on dry unit; Kal Kan meat; Kal Kan, Vernon, CA, and Purina Lab Chow; Purina Mills, St. Louis, MO) once daily. Each dog 
was used for only one experiment. The animals were housed in a facility that met American Association for the Accreditation of Laboratory Animal Care guidelines, and the protocols were approved by the Vanderbilt University Medical Center Animal Care Committee.

16-18 d before each experiment, a laparotomy was performed under general anesthesia (presurgery: $0.5 \mathrm{mg} / \mathrm{kg}$ atropine and $15 \mathrm{mg} / \mathrm{kg}$ thiopental [Pentothal] sodium; inhalation anesthetic during surgery: $1 . \%$ isoflurane), and silastic catheters were inserted into a splenic vein, a jejunal vein, the portal vein, the left common hepatic vein, and a femoral artery as described previously (12). Doppler flow probes (Instrumentation Development Laboratories, Baylor College of Medicine, Houston, TX) were placed around the portal vein and hepatic artery after the gastroduodenal vein had been ligated in order to drain blood back to the portal vein through the inferior pancreaticoduodenal vein as described elsewhere (13). The dogs received penicillin $\mathrm{G}$ intramuscularly $\left(10^{6} \mathrm{U}\right)$ immediately after surgery to minimize the possibility of infection. All dogs studied had: leukocyte count $<1,8000 / \mathrm{mm}^{3}$; a hematocrit $>35 \%$; a good appetite; and normal stools.

On the day of study, the free ends of the catheters and Doppler leads were removed from their subcutaneous pockets under local anesthesia ( $2 \%$ lidocaine; Astra Pharmaceutical Products, Worcester, MA). The catheter contents were aspirated, and saline was infused through them at a slow rate until the experiment was begun. The catheters in the splenic and jejunal veins were used for intraportal infusion of insulin, glucagon, and epinephrine. The portal vein, hepatic vein, and femoral artery catheters were used for blood sampling. Angiocaths (Deseret Medical, Becton Dickinson, Sandy, UT) were inserted into the left cephalic vein for indocyanine green dye (Becton Dickinson, Cockeysville, MD), $\left[3-{ }^{3} \mathrm{H}\right]$ glucose, and $\left[\mathrm{U}-{ }^{14} \mathrm{C}\right]$ alanine infusion. The right cephalic vein was used for peripheral epinephrine or glucose infusion, and the right saphenous vein for somatostatin infusion (Bachem, Torrance, CA). After preexperimental preparation, each dog was allowed to stand quietly in a Pavlov harness for 20-30 min before beginning the experiment.

Experimental design. Each experiment consisted of $100 \mathrm{~min}$ $(-140$ to $-40 \mathrm{~min})$ tracer equilibration and hormone adjustment period, a 40-min basal period ( -40 to $0 \mathrm{~min}$ ), and a 180-min experimental period $(0-180 \mathrm{~min})$. In all studies, a priming dose of purified $\left[3-{ }^{3} \mathrm{H}\right]$ glucose $(42 \mu \mathrm{Ci})$ was given at $-140 \mathrm{~min}$, followed by a constant infusion of $\left[3-{ }^{3} \mathrm{H}\right]$ glucose $(0.35 \mu \mathrm{Ci} / \mathrm{min}),\left[\mathrm{U}-{ }^{14} \mathrm{C}\right]$ alanine $(0.35 \mu \mathrm{Ci} /$ min and indocyanine green $\left(0.1 \mathrm{mg} / \mathrm{m}^{2} \cdot \mathrm{min}\right)$. An infusion of somatostatin $(0.8 \mu \mathrm{g} / \mathrm{kg} \cdot \mathrm{min})$ was started at $-130 \mathrm{~min}$ to inhibit endogenous insulin and glucagon secretion. Concurrently, intraportal replacement infusions of insulin $(300 \mu \mathrm{U} / \mathrm{kg} \cdot \mathrm{min})$ and glucagon $(0.65 \mathrm{ng} /$ $\mathrm{kg} \cdot \mathrm{min})$ were started. The plasma glucose level was monitored every 5 min and was maintained euglycemic by adjusting the rate of insulin infusion. The final alteration in the insulin infusion rate was made at least $30 \mathrm{~min}$ before the start of the basal period, and the rate of insulin infusion (mean of $235 \mu \mathrm{U} / \mathrm{kg} \cdot \mathrm{min}$ ) remained unchanged thereafter. Epinephrine, in a solution of $0.07 \%$ ascorbic acid, was infused during the experimental period. The study included three groups. In the first, (EPI po $)^{1}$ epinephrine $(8 \mathrm{ng} / \mathrm{kg} \cdot \mathrm{min})$ was infused via the splenic and jejunal vein catheters. In the second, (EPI pe) epinephrine $(80 \mathrm{ng} / \mathrm{kg} \cdot \mathrm{min})$ was infused via the right cephalic vein catheter. This rate was chosen based on our desire to create the same sinusoidal epinephrine levels as in the EPI po group. In the third group, (control) epinephrine $(0.3 \mathrm{ng} / \mathrm{kg} \cdot \mathrm{min})$ was infused via the right cephalic vein catheter in order to match the arterial epinephrine level in EPI po group. Arterial glucose levels in the EPI po and control groups were clamped to the level observed in the EPI pe group by infusing glucose ( $20 \%$ dextrose) via the right cephalic vein. Blood sam-

1. Abbreviations used in this paper: $\mathrm{BOHB}, \beta$-hydroxybutyrate; CV, coefficient of variation; EPI pe, peripherally infused epinephrine; EPI po, intraportally infused epinephrine; HGU, hepatic glucose uptake; NHGO, net hepatic glucose output. ples were taken every 20 min during the control period and every 15 min thereafter. The total volume of the blood withdrawn did not exceed $15 \%$ of the animal's total blood volume, and two volumes of the saline were given for each volume of blood taken. The collection and immediate processing of blood samples have been described elsewhere (4). The arterial and the portal blood samples were collected simultaneously $\sim 30 \mathrm{~s}$ before the collection of the hepatic venous samples in an attempt to compensate for the transit time of glucose through the liver (14). This allowed accurate estimates of net hepatic balance to be made even under non-steady state conditions.

Analytic procedures. Plasma glucose concentrations were determined using the glucose-oxidase method in a glucose analyzer (Beckman Instruments, Inc., Fullerton, CA). Blood glucose values were assumed to be $73 \%$ of the plasma values based on our earlier studies (12). Plasma $\left[{ }^{3} \mathrm{H}\right]$ glucose and $\left[{ }^{14} \mathrm{C}\right]$ glucose were determined by double-label liquid scintillation counting following Somogyi-Nelson deproteinization and $\left[{ }^{3} \mathrm{H}_{2} \mathrm{O}\right]$ exclusion procedures as described elsewhere (15). Blood glutamine and glutamate were assessed using an autoanalyzer (Technicon Instruments Corp., Tarrytown, NY) according to the method described by Wasserman et al. (16). Whole blood levels of lactate, glycerol, alanine, and $\beta$-hydroxybutyrate (BOHB) were determined according to the method of Lloyd et al. (17) adapted to a centrifugal analyzer (Monarch 2000; Monarch, Lexington, MA). Plasma nonesterified fatty acids (FFA) were measured using the Wako FFA C test kit (Wako Chemicals, Richmond, VA) applied to the Monarch 2000 centrifugal analyzer. Individual amino acid levels in blood were assessed using the method of Venkatakrishnan et al. with a coefficient of variation $(\mathrm{CV})$ of $4 \%(18) .\left[{ }^{14} \mathrm{C}\right]$ Alanine, $\left[{ }^{14} \mathrm{C}\right]$ lactate, and $\left[{ }^{14} \mathrm{C}\right]$ glucose specific activities were measured using a column chromatography method described elsewhere (19). The concentration of indocyanine green in arterial and hepatic vein plasma samples was measured using a spectrophotometer (805 nm) (20).

Immunoreactive insulin was measured using a double-antibody procedure (21). The interassay CV for insulin averaged $11 \%$. Levels of immunoreactive glucagon were measured using a double antibody RIA using a method similar to that used in the insulin assay with a $\mathrm{CV}$ of $8 \%$. Plasma epinephrine and norepinephrine levels were determined using HPLC as previously described (22) with interassay CVs of 7 and $5 \%$, respectively. Plasma cortisol levels were measured using a gamma coat radioimmunoassay (Clinical Assays, Cambridge, MA) with a $\mathrm{CV}$ of $6 \%$.

Tracer method and calculation. Indocyanine green dye (20) and Doppler flow probes (23) were used to estimate total hepatic blood flow. When the ICG method was used in the presence of a somatostatin infusion, the hepatic artery and portal vein were assumed to provide 28 and $72 \%$ of hepatic blood flow, respectively (20). The net hepatic balance and fractional extraction of blood glucose, lactate, glycerol, BOHB, alanine, other gluconeogenic amino acids, and plasma FFA in this study were calculated using the Doppler-determined flow:

Net hepatic substrate balance $=\{H-[A \cdot F a /(F a+F p)+$

$P \cdot F p /(F a+F p)]\} \cdot[F a+F p]$

Fractional extraction $=[H \cdot(F a+F p)-(A \cdot F a+P \cdot F p)] /$

$(A \cdot F a+P \cdot F p)$

Hepatic sinusoidal substrate level $=A \cdot F a /(F a+F p)+P \cdot F p /$

$(F a+F p)$

and indocyanine green-determined flow:

Net hepatic substrate balance $=[H-(0.28 A+0.72 P)] \cdot F h ;$

Fractional extraction $=[H-(0.28 A+0.72 P)] /(0.28 A+0.72 P) ;$

Hepatic sinusoidal substrate level $=(0.28 A+0.72 P) \cdot F h$;

where $\mathrm{A}, \mathrm{H}$, and $\mathrm{P}$ are the arterial, hepatic vein, and portal vein substrate concentrations (blood or plasma); $\mathrm{Fa}$ and $\mathrm{Fp}$ are the hepatic ar- 
terial and portal vein (blood or plasma) flow measured by the Dopplers; Fh is total hepatic (blood or plasma) flow calculated using the indocyanine green dye method. The total hepatic blood flows during the experimental period of the control, EPI po, and EPI pe groups were $28 \pm 2,27 \pm 3$, and $32 \pm 3 \mathrm{ml} / \mathrm{kg} \cdot \mathrm{min}$, respectively (measured using Dopplers) and $30 \pm 2,28 \pm 4$, and $32 \pm 2 \mathrm{ml} / \mathrm{kg} \cdot \mathrm{min}$, respectively (measured using indocyanine green dye). Since in our studies hepatic blood flows measured using the Doppler method were more stable than those determined using the indocyanine green dye method, the net hepatic substrate balance data shown in the figures and tables are those calculated using Doppler-determined flow. However, it should be noted that the conclusions drawn would be identical regardless of which flows were used in data calculation. Positive numbers for hepatic substrate balance indicate net liver output, while negative numbers indicate net liver uptake. It should be noted, to the extent that there was a hepatic glucose uptake (HGU), total hepatic glucose release (NHGO + HGU) would be slightly greater than net hepatic glucose output (NHGO). In the basal period of the current study this would cause a $10 \%$ difference (12). However, since an increment in the hepatic sinusoidal epinephrine level increases hepatic glucose production and decreases hepatic glucose utilization, it is likely that total hepatic glucose release during the experimental period would be indistinguishable from NHGO in the EPI pe and EPI po groups. In the control group, hyperglycemia per se would be expected to increase HGU slightly $(0.1-0.2 \mathrm{mg} / \mathrm{kg} \cdot \mathrm{min})$ as indicated by Pagliossotti et al. (24).

Total glucose production and utilization were determined using the isotope dilution method outlined by Wall et al. (25) as simplified by DeBodo et al. (26), and a two compartment model described by Mari (27) using parameters for the dog determined by Dobbins et al. (28). The results were similar regardless of which approach was used because the deviations from steady state were minimal. Glucose production and utilization data shown in the figures and tables are those calculated using the two compartment method. It should also be noted, since both the liver and kidney produce glucose, that the rate of endogenous glucose production determined by the tracer method slightly overestimates total hepatic glucose release (12).

Gluconeogenesis was assessed using a double-isotope technique described elsewhere (19). This technique involves the simultaneous infusion of two tracers, $\left[\mathrm{U}_{-}{ }^{14} \mathrm{C}\right]$ alanine to provide labeled substrate for the gluconeogenic pathway and $\left[3-{ }^{3} \mathrm{H}\right]$ glucose to measure endogenous $\left[{ }^{14} \mathrm{C}\right]$ glucose production. Once the $\left[{ }^{14} \mathrm{C}\right]$ glucose production rate is determined, gluconeogenic efficiency can be calculated by dividing the $\left[{ }^{14} \mathrm{C}\right]$ glucose production by the rate of net $\left[{ }^{14} \mathrm{C}\right]$ alanine and $\left[{ }^{14} \mathrm{C}\right]$ lactate uptake by the liver. Since the conversion of $\left[{ }^{14} \mathrm{C}\right]$ alanine to $\left[{ }^{14} \mathrm{C}\right]$ glucose by the kidney is minimal $(29),\left[{ }^{14} \mathrm{C}\right]$ glucose production is almost exclusively attributable to the liver. When net hepatic $\left[{ }^{14} \mathrm{C}\right]$ lactate production occurred, its net uptake was considered to be zero as noted previously (4). The above equations yield minimal estimates of hepatic gluconeogenesis because of the dilution of the $\left[{ }^{14} \mathrm{C}\right]$ precursor specific activity that occurs within the oxaloacetate pool of the hepatocyte and also because they assess gluconeogenesis from only two precursors. A maximal estimate of hepatic gluconeogenesis from circulating precursors can be obtained by assuming that all gluconeogenic carbons taken up by the liver in a net sense are converted to glucose. In these studies, the net hepatic balances of the gluconeogenic precursors, alanine, glycine, serine, threonine, glutamine, glutamate, lactate, and glycerol were measured. The net hepatic balance of pyruvate was assumed to be $10 \%$ of lactate balance (30). The maximal hepatic gluconeogenic rate was calculated by dividing the above uptake rates by two to account for the incorporation of three carbon precursors into six carbon glucose molecules. Multiplying this maximum estimate of gluconeogenesis by the tracer-determined gluconeogenic efficiency yields a minimum estimate of the hepatic gluconeogenic rate. Thus the rate of hepatic gluconeogenesis from circulating precursors can be bracketed between the maximal estimate obtained using arteriovenous techniques and the minimal estimate obtained using combined tracer and arteriovenous difference data.
Once the maximal and minimal gluconeogenic rates are obtained, the glycogenolytic rate in the liver can be estimated by subtraction of either the maximal or minimal gluconeogenic rate from net hepatic glucose balance or tracer-determined endogenous glucose production. Since a recent study in the $\operatorname{dog}$ (31) showed that the maximal rate of gluconeogenesis is a better estimate of the tracer gluconeogenic rate (directly determined using the method of Giaccari [32]) than is the minimal gluconeogenic rate, hepatic glycogenolysis (see Figs. 13 and 14) can be estimated by subtraction of the maximal gluconeogenic rate from either tracer-determined endogenous glucose production or NHGO. Since latter is the more representative of total hepatic glucose release, it provides the better estimates of glycogenolysis.

Statistical analysis. All statistical comparisons were made using repeated measures ANOVA and univariate F tests or paired Student's $t$ test where appropriate. Statistical significance was accepted at $P<0.05$. Data are expressed as means \pm SE.

\section{Results}

Hormone levels. The arterial and portal plasma levels of insulin, glucagon, and norepinephrine remained at basal values in all groups throughout the study (Figs. 1-3) as did the plasma cortisol level (data not shown). The arterial plasma levels of epinephrine remained essentially unchanged throughout the control $(99 \pm 25$ to $132 \pm 41 \mathrm{pg} / \mathrm{ml})$ and EPI po $(97 \pm 29$ to

$\sum \quad$ Pancreatic Clamp

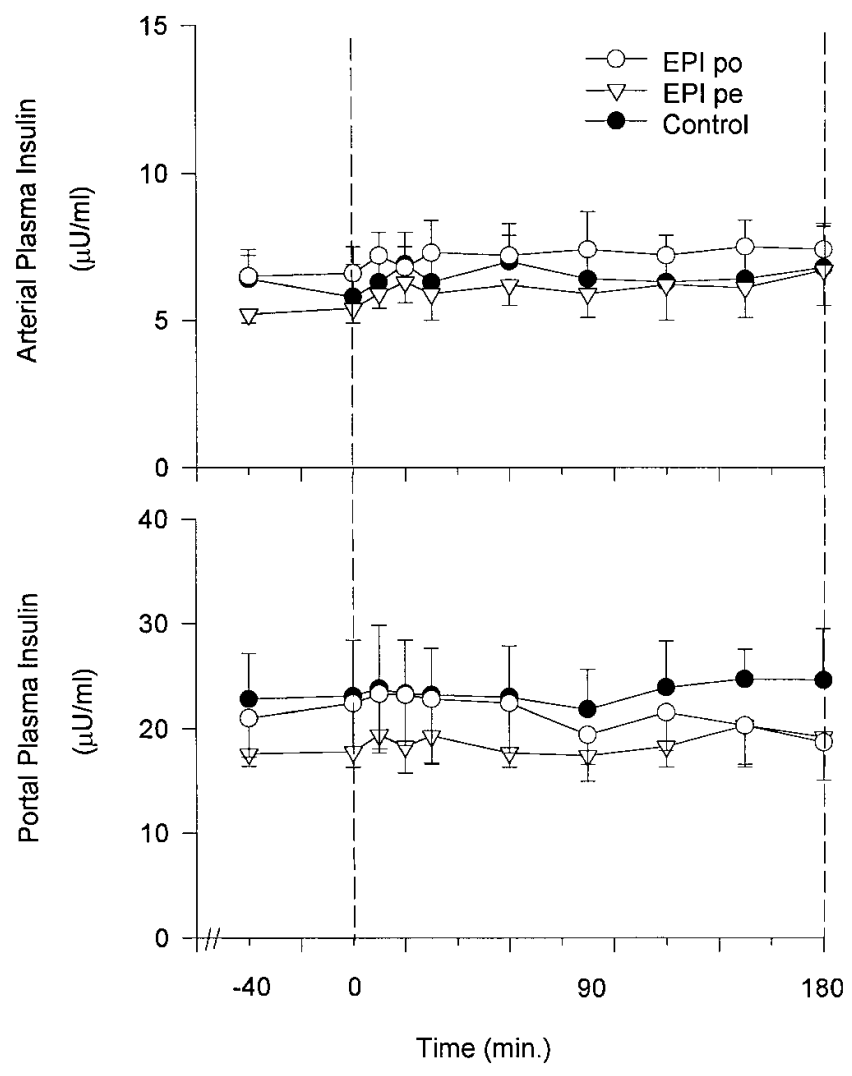

Figure 1. Arterial and portal plasma levels of insulin during the basal and experimental periods in the presence of a pancreatic clamp in conscious 18 -h-fasted dogs. Data are means \pm SE. 

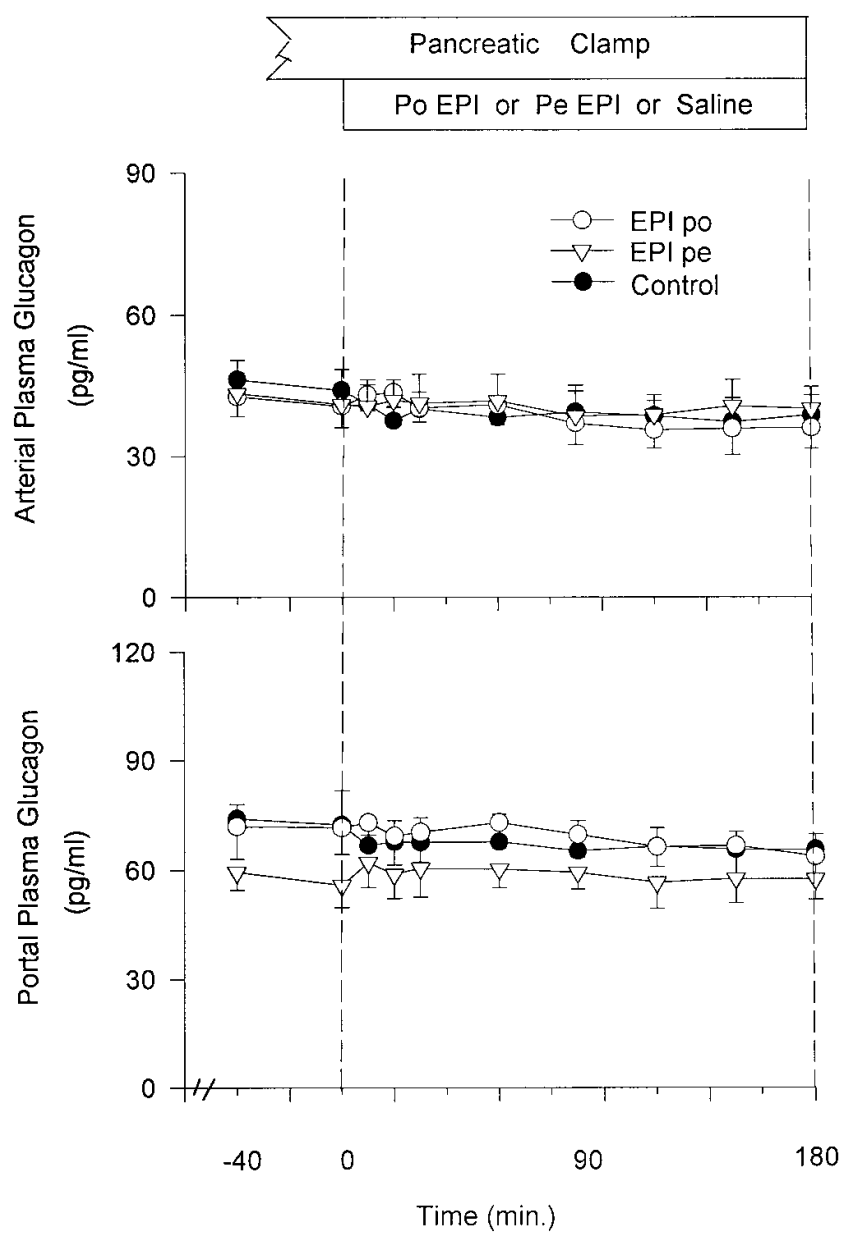

Figure 2. Arterial and portal plasma levels of glucagon during the basal and experimental periods in the presence of a pancreatic clamp in conscious 18 - $\mathrm{h}-$ fasted dogs. Data are means \pm SE.

$107 \pm 37$ pg/ml, Fig. 4) studies. Peripheral infusion of epinephrine increased the arterial plasma epinephrine level from $42 \pm 12$ to $1,064 \pm 144 \mathrm{pg} / \mathrm{ml}$. The portal plasma levels of epinephrine remained constant in the control group (16 \pm 10 to $24 \pm 12 \mathrm{pg} / \mathrm{ml}$ ) but rose in the EPI po group ( $27 \pm 10$ to $680 \pm 103$ $\mathrm{pg} / \mathrm{ml}$ ) and the EPI pe group (14 \pm 6 to $465 \pm 75 \mathrm{pg} / \mathrm{ml})$. The he-
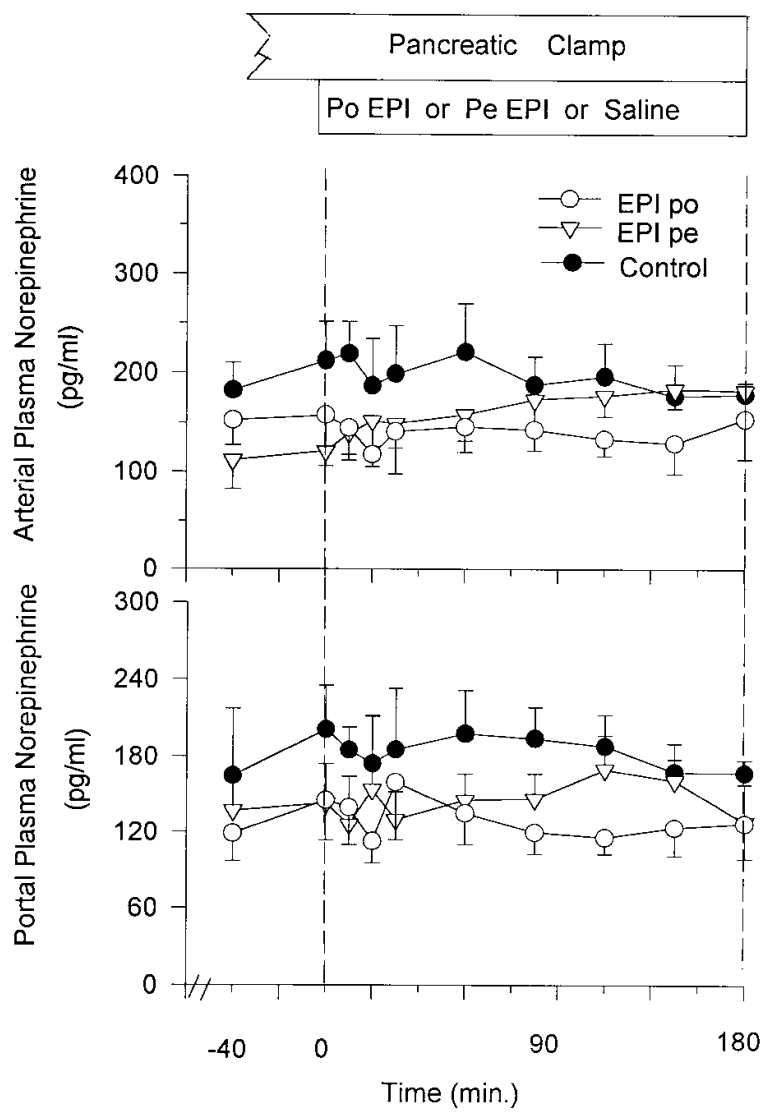

Figure 3. Arterial and portal plasma levels of norepinephrine during the basal and experimental periods in the presence of a pancreatic clamp in conscious 18 -h-fasted dogs. Data are means \pm SE.

patic sinusoidal levels of epinephrine remained unchanged in the control study but rose equivalently $20 \pm 8$ to $568 \pm 75$ and $42 \pm 14$ to $561 \pm 84 \mathrm{pg} / \mathrm{ml}$, respectively) in the EPI pe and EPI po groups.

Hepatic blood flow, arterial blood pressure, and heart rate. Hepatic blood flow remained stable in all groups throughout the study (Fig. 5). The systolic, diastolic (data not shown), and mean arterial blood pressures did not change significantly in any group (Fig. 5). The heart rate increased slightly in EPI pe

Table I. Tracer-determined Glucose Utilization and Clearance during the Basal and Saline versus Portal or Peripheral Epinephrine Infusion Periods in the Presence of a Pancreatic Clamp in Conscious 18-h-fasted Dogs

\begin{tabular}{|c|c|c|c|c|c|c|c|c|c|c|}
\hline \multirow[b]{2}{*}{ Time $(\min )$} & \multicolumn{2}{|c|}{ Basal period } & \multicolumn{8}{|c|}{ Saline versus portal or peripheral epinephrine infusion periods } \\
\hline & -40 & 0 & 10 & 20 & 30 & 60 & 90 & 120 & 150 & 180 \\
\hline \multicolumn{11}{|c|}{ Glucose utilization $(\mathrm{mg} / \mathrm{kg} \cdot \mathrm{min})$} \\
\hline Control & $2.5 \pm 0.3$ & $2.3 \pm 0.2$ & $2.3 \pm 0.3$ & $2.7 \pm 0.6$ & $2.7 \pm 0.4$ & $3.0 \pm 0.3$ & $2.9 \pm 0.2$ & $3.4 \pm 0.3 *$ & $3.7 \pm 0.2 *$ & $3.5 \pm 0.3 *$ \\
\hline EPI po & $2.5 \pm 0.3$ & $2.7 \pm 0.3$ & $3.0 \pm 0.3$ & $3.2 \pm 0.5$ & $3.6 \pm 0.4^{*}$ & $3.7 \pm 0.5^{*}$ & $3.8 \pm 0.5^{*}$ & $3.8 \pm 0.4^{*}$ & $3.8 \pm 0.4^{*}$ & $3.8 \pm 0.4 *$ \\
\hline EPI pe & $2.4 \pm 0.2$ & $2.2 \pm 0.1$ & $2.8 \pm 0.2$ & $2.8 \pm 0.3$ & $2.5 \pm 0.1^{\ddagger}$ & $2.5 \pm 0.2^{\ddagger}$ & $2.5 \pm 0.2^{\ddagger}$ & $2.7 \pm 0.3^{\ddagger}$ & $2.9 \pm 0.2$ & $2.9 \pm 0.2$ \\
\hline \multicolumn{11}{|c|}{ Clearance $(\mathrm{ml} / \mathrm{kg} \cdot \min )$} \\
\hline Control & $2.3 \pm 0.2$ & $2.1 \pm 0.2$ & $2.0 \pm 0.3$ & $2.2 \pm 0.5$ & $2.1 \pm 0.3$ & $2.0 \pm 0.2$ & $1.8 \pm 0.1$ & $2.1 \pm 0.2$ & $2.3 \pm 0.1$ & $2.1 \pm 0.2$ \\
\hline EPI po & $2.4 \pm 0.3$ & $2.6 \pm 0.3$ & $2.6 \pm 0.3$ & $2.7 \pm 0.3$ & $2.8 \pm 0.3$ & $2.5 \pm 0.4$ & $2.4 \pm 0.3$ & $2.3 \pm 0.2$ & $2.3 \pm 0.3$ & $2.3 \pm 0.2$ \\
\hline EPI pe & $2.3 \pm 0.2$ & $2.1 \pm 0.2$ & $2.4 \pm 0.2$ & $2.1 \pm 0.2$ & $2.0 \pm 0.2^{\ddagger}$ & $1.7 \pm 0.1 * \ddagger$ & $1.6 \pm 0.1 * \ddagger$ & $1.7 \pm 0.2 *$ & $1.8 \pm 0.2$ & $1.8 \pm 0.2$ \\
\hline
\end{tabular}

${ }^{*} P<0.05$ vs. corresponding basal period. ${ }^{\ddagger} P<0.05$ difference between the EPI pe and EPI po groups. Data are means \pm SE. 


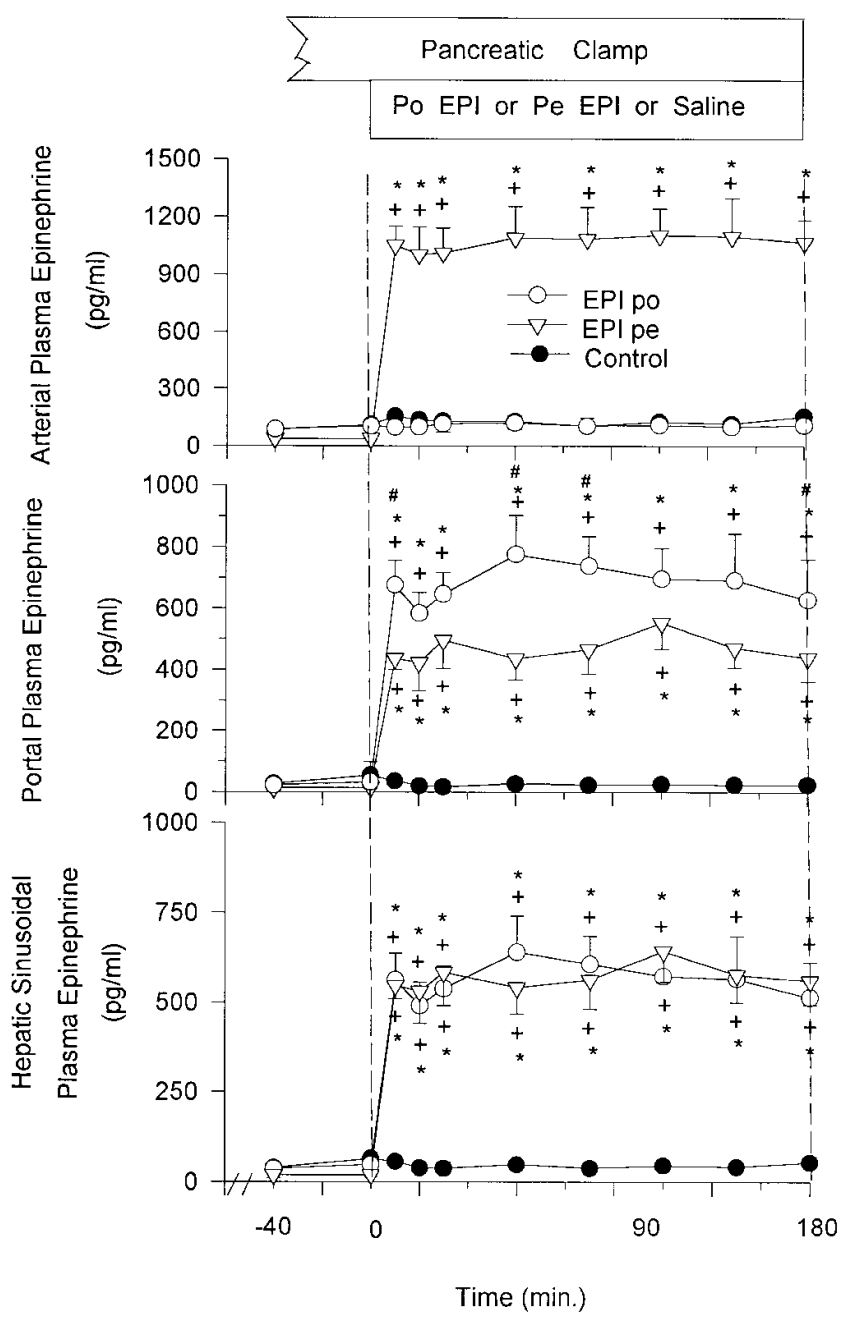

Figure 4. Plasma epinephrine levels in artery, portal vein, and hepatic sinusoid during the basal and experimental periods in the presence of a pancreatic clamp in conscious 18 -h-fasted dogs. Data are means \pm SE. ${ }^{+} P<0.05$, difference between the EPI (pe or po) and control groups. ${ }^{\#} P<0.05$, difference between the EPI pe and EPI po groups. ${ }^{*} P<0.05$ vs. corresponding basal period.

group but did not change significantly in the other two groups (Fig. 5).

Glucose levels and kinetics. During peripheral catecholamine infusion the arterial blood glucose level gradually rose from $77 \pm 3$ to $118 \pm 5 \mathrm{mg} / \mathrm{dl}$ (by $90 \mathrm{~min}$ ) and remained constant thereafter (Fig. 6). The arterial glucose levels in the control $79 \pm 4$ to $120 \pm 3 \mathrm{mg} / \mathrm{dl})$ and EPI po $(77 \pm 2$ to $124 \pm 3 \mathrm{mg} / \mathrm{dl})$ groups were clamped to the level seen in the EPI pe group. In response to the peripheral infusion of epinephrine, NHGO increased from $2.2 \pm 0.1$ to $5.1 \pm 0.2 \mathrm{mg} / \mathrm{kg} \cdot \mathrm{min}$ by $10 \mathrm{~min}(P<$ $0.05)$ and then fell back to $2.6 \pm 0.4 \mathrm{mg} / \mathrm{kg} \cdot \mathrm{min}$ by the end of the study (Fig. 6). In response to the portal infusion of epinephrine, NHGO increased from $2.1 \pm 0.1$ to $3.8 \pm 0.6 \mathrm{mg} / \mathrm{kg} \cdot \mathrm{min}$ by $10 \mathrm{~min}(P<0.05)$ and then gradually fell back to $2.0 \pm 0.4 \mathrm{mg} /$ $\mathrm{kg} \cdot \mathrm{min}$. The initial increases in NHGO in response to epinephrine infusion in the EPI pe and EPI po groups were significantly different $(P<0.05$, Fig. 6$)$. In the presence of the hyperglycemic clamp alone (control), NHGO fell from 2.1 \pm 0.1 to

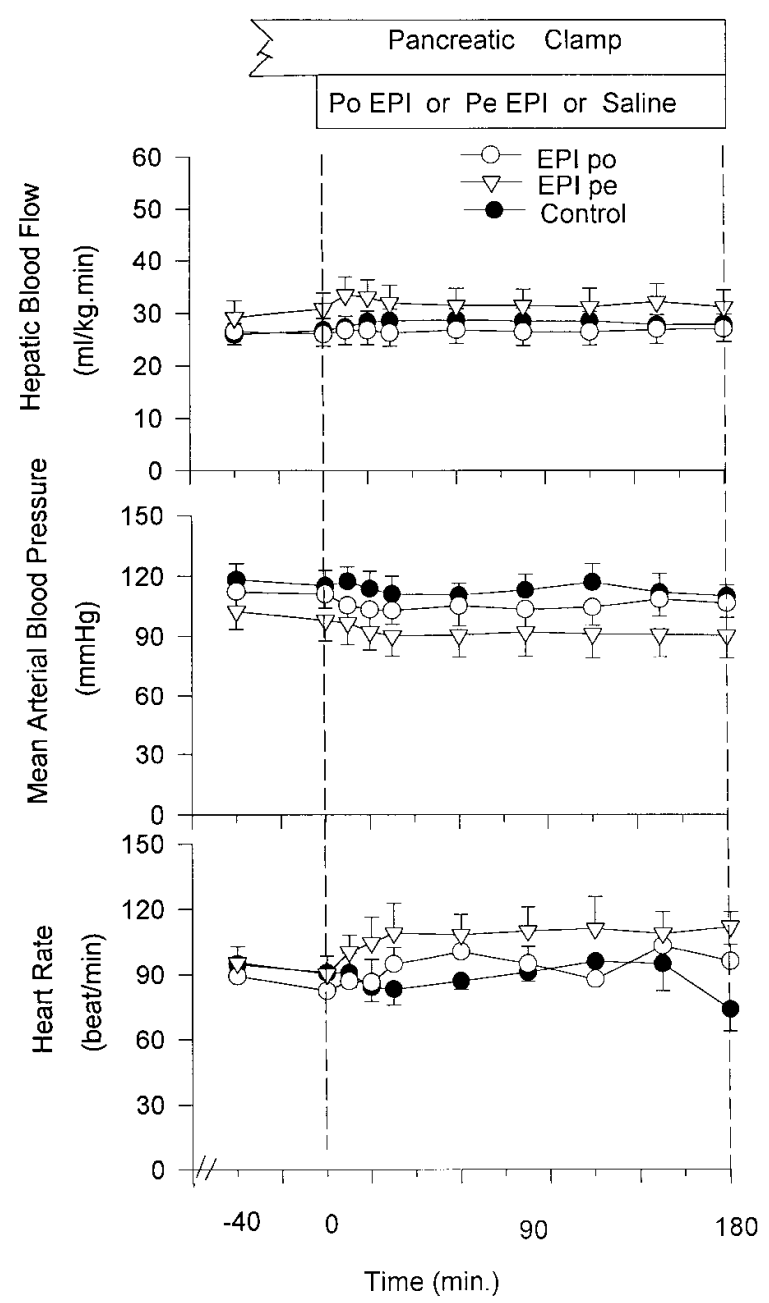

Figure 5. Hepatic blood flow, mean arterial blood pressure, and heart rate during the basal and experimental periods in the presence of a pancreatic clamp in conscious $18-\mathrm{h}-$ fasted dogs. Data are means \pm SE.

$1.0 \pm 0.2 \mathrm{mg} / \mathrm{kg} \cdot \min (P<0.05)$ by the end of the study. The changes in tracer-determined endogenous glucose production paralleled those in NHGO in all three groups (Fig. 6). During the experimental period, tracer-determined glucose utilization in the EPI pe group increased from $2.3 \pm 0.1$ to $2.8 \pm 0.2 \mathrm{mg} /$ $\mathrm{kg} \cdot \mathrm{min}$ within $10 \mathrm{~min}$ and remained stable thereafter (Table I). In the EPI po group, it increased from $2.6 \pm 0.3$ to $3.8 \pm 0.5 \mathrm{mg} /$ $\mathrm{kg} \cdot \min$ by $90 \mathrm{~min}(P<0.05)$ and then remained stable. In the control group it gradually increased from $2.4 \pm 0.2$ to $3.6 \pm 0.2$ $\mathrm{mg} / \mathrm{kg} \cdot \mathrm{min}$ (last $30 \mathrm{~min})(P<0.05)$. Glucose clearance in the EPI pe group fell from $2.2 \pm 0.2$ to $1.7 \pm 0.1 \mathrm{mg} / \mathrm{kg} \cdot \mathrm{min}(P<$ 0.05 ) by $60 \mathrm{~min}$ and was stable thereafter. Glucose clearance in the other two groups remained essentially unchanged (Table I).

Arterial blood level, net hepatic uptake, and fractional extraction of alanine. The arterial alanine levels remained essentially unchanged in the control and EPI po groups, but increased from $283 \pm 40$ to $576 \pm 73 \mu \mathrm{mol} /$ liter $(P<0.05)$ in the EPI pe group (Fig. 7). Net hepatic alanine uptake increased from $2.8 \pm 0.4$ to $3.6 \pm 0.4$ (NS), $3.0 \pm 0.3$ to $4.0 \pm 0.5$ (NS), and $3.1 \pm 0.4$ to $4.9 \pm 0.5(P<0.05) \mu \mathrm{mol} / \mathrm{kg} \cdot \mathrm{min}$ in the control, EPI po, and EPI pe groups, respectively, by the end of the study 


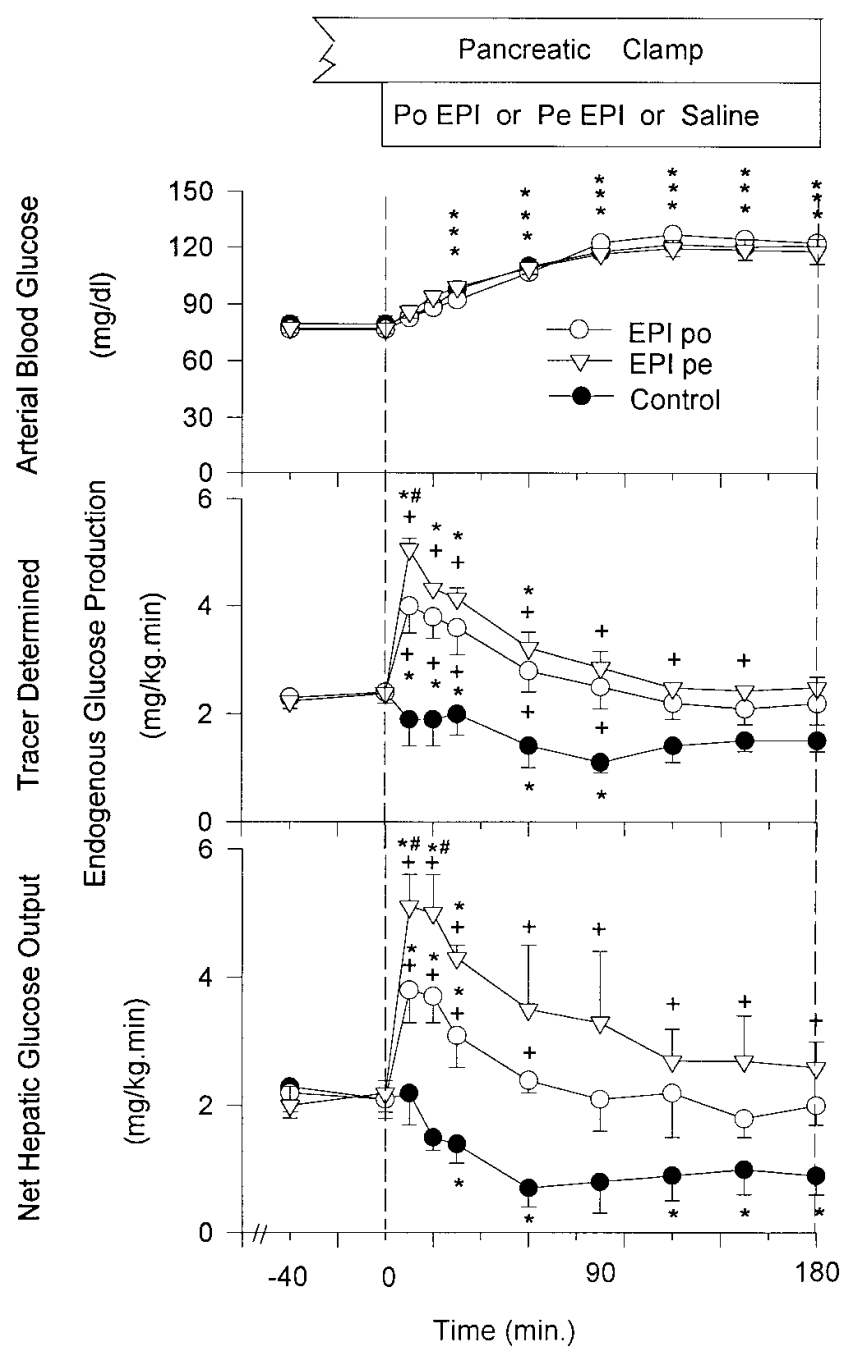

Figure 6. Arterial blood glucose level, tracer-determined endogenous glucose production, and NHGO during the basal and experimental periods in the presence of a pancreatic clamp in conscious 18-h-fasted dogs. Data are means \pm SE. ${ }^{+} P<0.05$ difference between the EPI (pe or po) and control groups. ${ }^{\#} P<0.05$ difference between the EPI pe and EPI po groups. ${ }^{*} P<0.05$ vs. corresponding basal period.

(Fig. 7). The net hepatic fractional alanine extraction in the control and EPI pe groups increased from $0.34 \pm 0.02$ to $0.41 \pm 0.03$ and $0.31 \pm 0.03$ to $0.38 \pm 0.03$ in $10 \mathrm{~min}$, respectively (NS, Fig. 7), then gradually fell back to baseline. In the EPI po group it rose from $0.38 \pm 0.02$ to $0.52 \pm 0.05(P<0.05)$ by the end of the study.

Arterial blood level and net hepatic balance of lactate. The arterial blood lactate levels did not change significantly in the control and EPI po groups (Fig. 8), but rose from $563 \pm 72$ to $3,831 \pm 403 \mu \mathrm{mol} /$ liter $(P<0.01)$ in the EPI pe group. Net hepatic lactate balance in the control group changed from net uptake to net output $(-2.9 \pm 1.5$ to $3.9 \pm 3.1 \mu \mathrm{mol} / \mathrm{kg} \cdot \mathrm{min}$, Fig. 8$)$. In response to the portal infusion of epinephrine, lactate balance changed rapidly $(10 \mathrm{~min})$ from net uptake to net output $(-1.0 \pm 1.5$ to $6.6 \pm 2.8 \mu \mathrm{mol} / \mathrm{kg} \cdot \mathrm{min}, P<0.05)$. In response to the peripheral infusion of epinephrine, net hepatic lactate up-
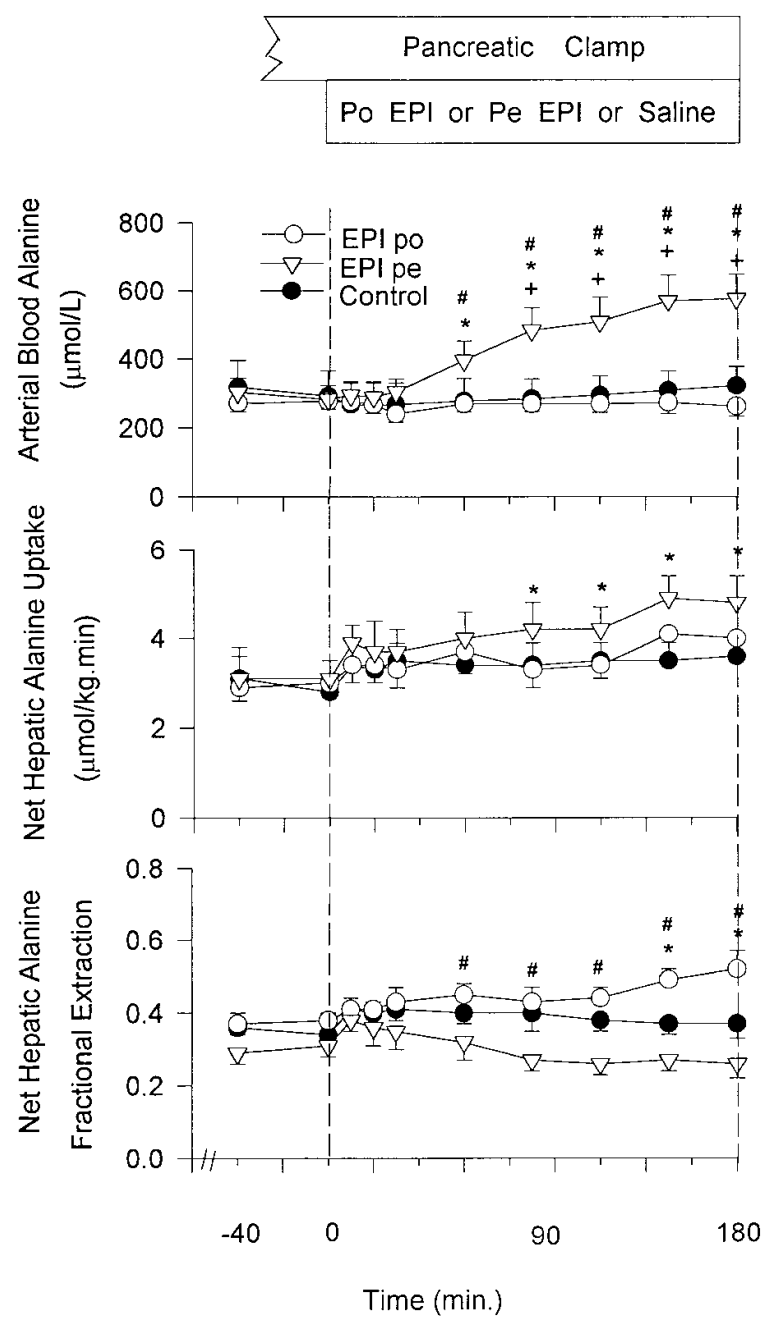

Figure 7. Arterial blood alanine, net hepatic uptake, and fractional extraction during the basal and experimental periods in the presence of a pancreatic clamp in conscious 18 -h-fasted dogs. Data are means \pm SE. ${ }^{+} P<0.05$ difference between the EPI (pe or po) and control groups. ${ }^{\#} P<0.05$ difference between the EPI pe and EPI po groups. $* P<0.05$ vs. corresponding basal period.

take rose dramatically $(-1.0 \pm 2.4$ to $-12.4 \pm 4.6 \mu \mathrm{mol} / \mathrm{kg} \cdot \mathrm{min}$, $P<0.05$.

Arterial blood level, net hepatic uptake, and fractional extraction of glycerol. The blood glycerol level and net hepatic glycerol uptake in the control and EPI po groups remained essentially unchanged throughout the study (Fig. 9). In response to peripheral infusion of epinephrine, the blood glycerol increased from $86 \pm 14$ to $181 \pm 21 \mu \mathrm{mol} /$ liter $(P<0.05)$ in $10 \mathrm{~min}$ while net hepatic glycerol uptake rose from $1.5 \pm 0.3$ to $3.4 \pm 0.4$ $\mu \mathrm{mol} / \mathrm{kg} \cdot \min (P<0.05)$ (Fig. 9). Thereafter, both the blood level and net hepatic uptake of glycerol gradually fell. Net hepatic glycerol fractional extraction remained essentially unchanged in all groups (Fig. 9).

Arterial plasma level, net hepatic uptake, and fractional extraction of FFA. The arterial plasma FFA levels in the control and EPI po groups were stable throughout the study (Fig. 10). Net hepatic FFA uptake in those two groups increased slightly at the beginning of the experimental period (10-30 $\mathrm{min})$ and 


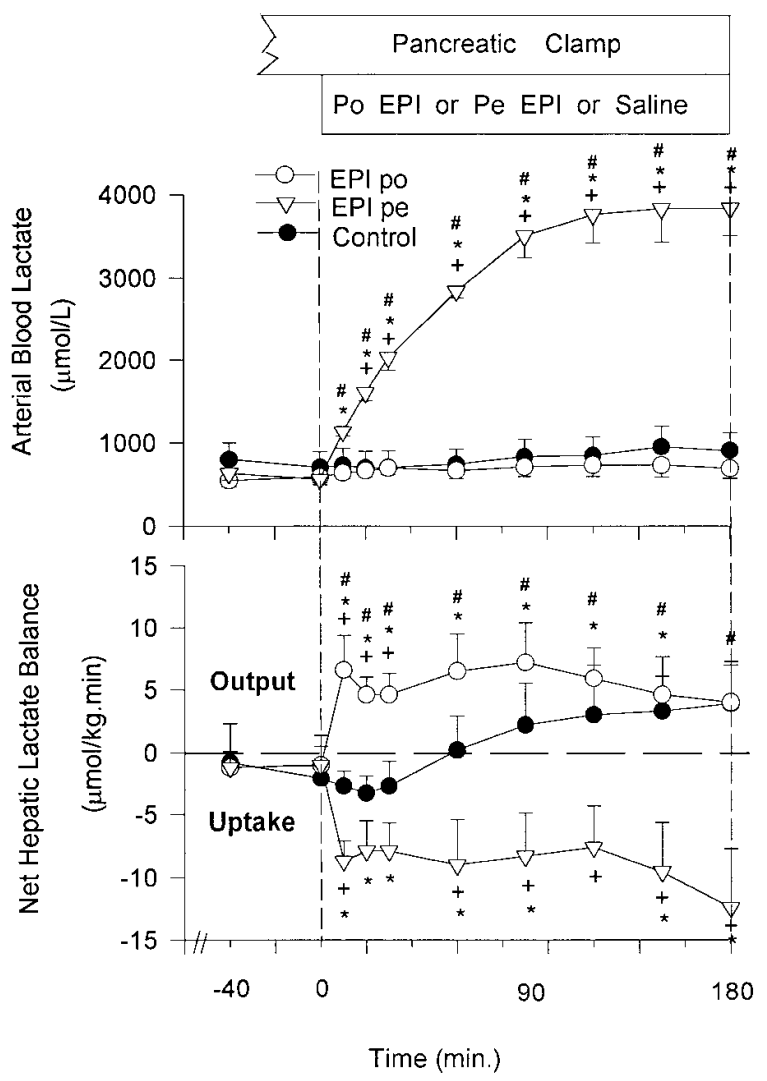

Figure 8. Arterial blood lactate and net hepatic balance during the basal and experimental periods in the presence of a pancreatic clamp in conscious 18 - $\mathrm{h}$-fasted dogs. Data are means \pm SE. ${ }^{+} P<0.05$ difference between the EPI (pe or po) and control groups. ${ }^{\#} P<0.05$ difference between the EPI pe and EPI po groups. $* P<0.05$ vs. corresponding basal period.

then drifted back to the baseline by the end of study (Fig. 10). In response to peripheral epinephrine infusion, both the arterial plasma FFA level and net hepatic FFA uptake increased significantly by $20 \mathrm{~min}(903 \pm 126$ to $1,611 \pm 139 \mu \mathrm{mol} /$ liter, $P<$ 0.05 and $3.5 \pm 0.6$ to $7.8 \pm 1.0 \mu \mathrm{mol} / \mathrm{kg} \cdot \mathrm{min}, P<0.05)$ and then gradually fell below baseline $(381 \pm 74 \mu \mathrm{mol} /$ liter and $1.3 \pm 0.7$ $\mu \mathrm{mol} / \mathrm{kg} \cdot \mathrm{min}$, respectively). Net hepatic FFA fractional extraction increased slightly but not significantly in the early part of the experimental period in all groups, but by $60 \mathrm{~min}$ had returned to baseline (Fig. 10).

Arterial blood level and net hepatic output of $\mathrm{BOHB}$. Both the arterial blood BOHB level and net hepatic BOHB output increased slightly during the initial stage of the experimental period in the control and EPI po groups and then fell back to baseline (Fig. 11). In response to peripheral epinephrine infusion, arterial BOHB and net hepatic BOHB output increased from $30 \pm 4$ to $42 \pm 4 \mu \mathrm{mol} / \mathrm{liter}(P<0.05)(20 \mathrm{~min})$ and from $1.2 \pm 0.2$ to $1.9 \pm 0.3 \mu \mathrm{mol} / \mathrm{kg} \cdot \min (P<0.05)(10 \mathrm{~min})$, respectively. Both parameters had fallen below baseline $(15 \pm 3$ $\mu \mathrm{mol} / \mathrm{liter}$ and $0.7 \pm 0.1 \mu \mathrm{mol} / \mathrm{kg} \cdot \mathrm{min}$, respectively) by the end of study.

Arterial blood levels and net hepatic balances of gluconeogenic amino acids. The arterial blood levels and net hepatic balances of the gluconeogenic amino acids were not significantly altered by any treatment (Table II).

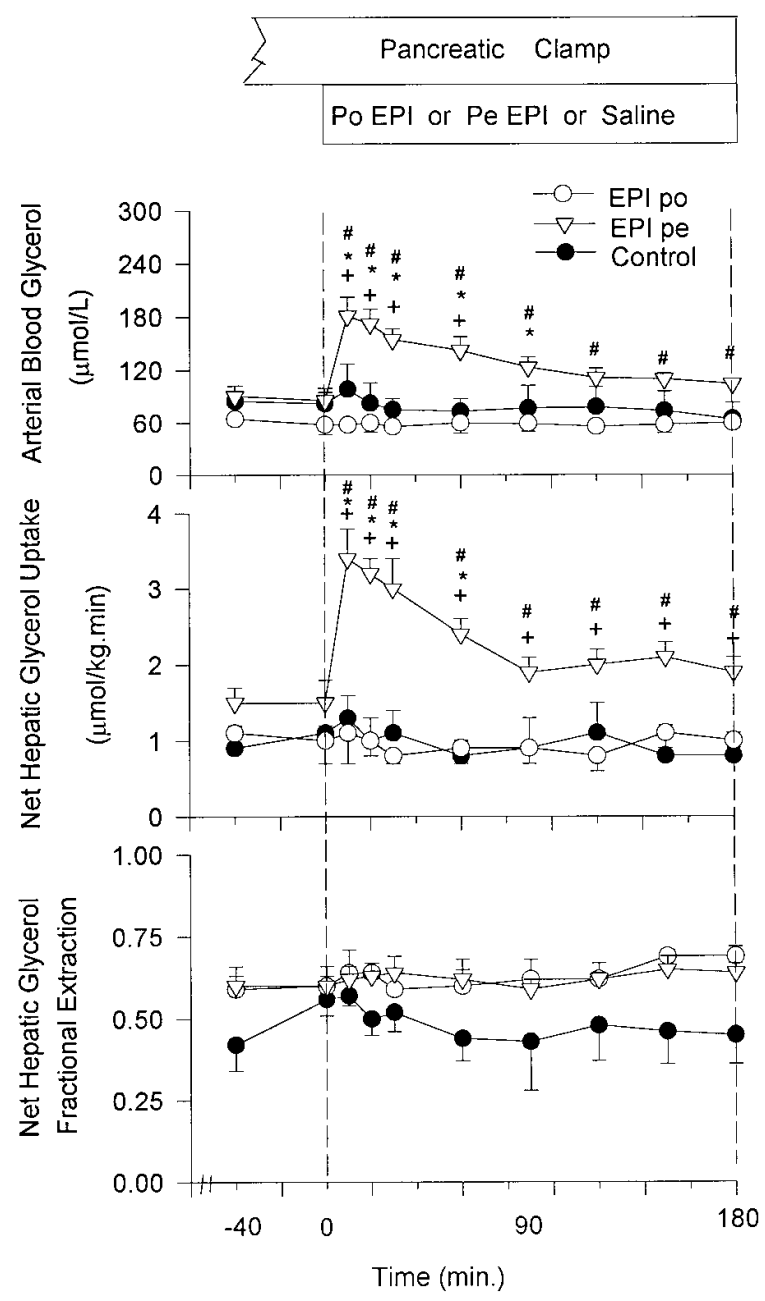

Figure 9. Arterial blood glycerol, net hepatic uptake, and fractional extraction during the basal and experimental periods in the presence of a pancreatic clamp in conscious 18 -h-fasted dogs. Data are means \pm SE. ${ }^{+} P<0.05$ difference between the EPI (pe or po) and control groups. ${ }^{\sharp} P<0.05$ difference between the EPI pe and EPI po groups. ${ }^{*} P<0.05$ vs. corresponding basal period.

Gluconeogenic parameters. The gluconeogenic efficiency ( $35 \pm 6$ to $41 \pm 8 \%)$, as well as maximal $(0.8 \pm 0.4$ to $0.7 \pm 4 \mathrm{mg} /$ $\mathrm{kg} \cdot \mathrm{min})$ and minimal $(0.3 \pm 0.1$ to $0.3 \pm 0.1 \mathrm{mg} / \mathrm{kg} \cdot \mathrm{min})$ gluconeogenic rates, were essentially unchanged in the control group (Fig. 12). In the EPI po group, gluconeogenic efficiency fell slightly ( $35 \pm 6$ to $26 \pm 6 \%$, NS) but the minimal and maximal gluconeogenic rates did not change $(0.3 \pm 0.1$ to $0.2 \pm 0.0$ $\mathrm{mg} / \mathrm{kg} \cdot \mathrm{min}$ and $0.8 \pm 0.5$ to $0.7 \pm 0.2 \mathrm{mg} / \mathrm{kg} \cdot \mathrm{min}$, respectively) (Fig. 12). During peripheral epinephrine infusion, gluconeogenic efficiency increased from $35 \pm 5$ to $62 \pm 9 \%$ in $10 \mathrm{~min}$ $(P<0.05)$ and then gradually fell back to $42 \pm 7 \%$ by the end of the study (Fig. 12). The maximal gluconeogenic rate increased from $0.7 \pm 0.4$ to $1.8 \pm 0.5 \mathrm{mg} / \mathrm{kg} \cdot \min (P<0.05)$ by $10 \mathrm{~min}$, and then rose further to $2.2 \pm 0.7 \mathrm{mg} / \mathrm{kg} \cdot \mathrm{min}(P<0.05)$. The minimal gluconeogenic rate increased from $0.3 \pm 0.1$ to $1.1 \pm 0.4 \mathrm{mg} / \mathrm{kg} \cdot \mathrm{min}(P<0.05)$ by $10 \mathrm{~min}$ and then remained elevated until the end of the study. The changes in gluconeogenic efficiency as well as the minimal and maximal gluconeo- 

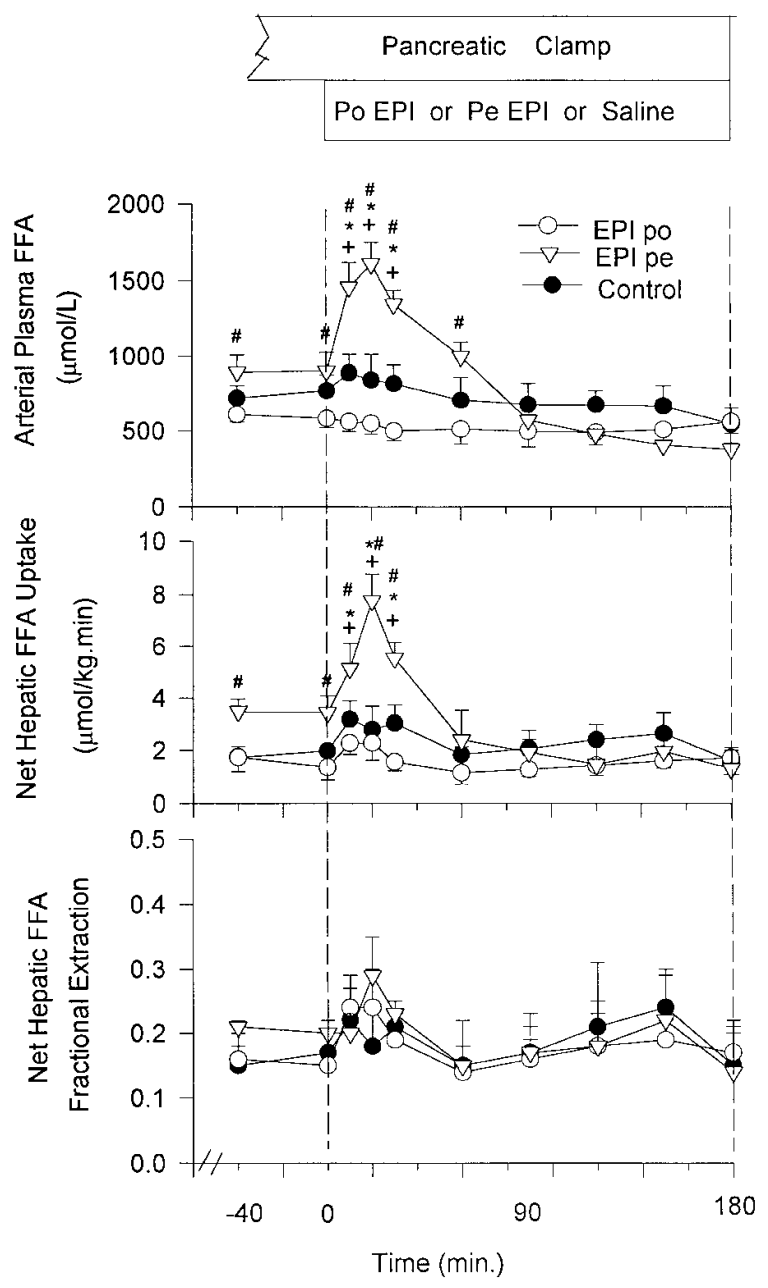

Figure 10. Arterial plasma FFA, net hepatic uptake, and fractional extraction during the basal and experimental periods in the presence of a pancreatic clamp in conscious 18 -h-fasted dogs. Data are means \pm SE. ${ }^{+} P<0.05$ difference between the EPI (pe or po) and control groups. ${ }^{\#} P<0.05$ difference between the EPI pe and EPI po groups. $* P<0.05$ vs. corresponding basal period.

genic rates were significantly different $(P<0.05)$ in the EPI pe and EPI po groups (Fig. 12).

Hepatic glycogenolytic rates. Hepatic glycogenolysis was similar in all three groups during the basal period (Fig. 13). In response to hyperglycemia alone, the glycogenolytic rate decreased moderately from $1.4 \pm 0.4$ to $0.7 \pm 0.2 \mathrm{mg} / \mathrm{kg} \cdot \mathrm{min}$ in $90 \mathrm{~min}$ and remained suppressed by the end of the study. In response to the portal infusion of epinephrine, glycogenolysis increased from $1.4 \pm 0.4$ to $3.8 \pm 1.1 \mathrm{mg} / \mathrm{kg} \cdot \min (P<0.05)$ in $(10 \mathrm{~min})$ and then gradually fell to $1.6 \pm 0.6 \mathrm{mg} / \mathrm{kg} \cdot \mathrm{min}$. In response to the peripheral infusion of epinephrine, glycogenolysis increased from $1.5 \pm 0.7$ to $3.2 \pm 1.1 \mathrm{mg} / \mathrm{kg} \cdot \min (P<0.05)$ in $10 \mathrm{~min}$ but eventually was markedly suppressed $(0.4 \pm 0.1 \mathrm{mg} /$ $\mathrm{kg} \cdot \min , P<0.05)$. The average rate of glycogenolysis over the entire experimental period fell from $1.4 \pm 0.4$ to $0.8 \pm 0.2 \mathrm{mg} /$ $\mathrm{kg} \cdot \mathrm{min}$ in the control group. The average increment in hepatic glycogenolysis induced by epinephrine was significantly $(P<$ $0.05)$ greater in the EPI po group $(1.4 \pm 0.3 \mathrm{mg} / \mathrm{kg} \cdot \mathrm{min})$ than in the EPI pe group (0.6 $\pm 0.1 \mathrm{mg} / \mathrm{kg} \cdot \mathrm{min})$ (Fig. 14). A similar con-
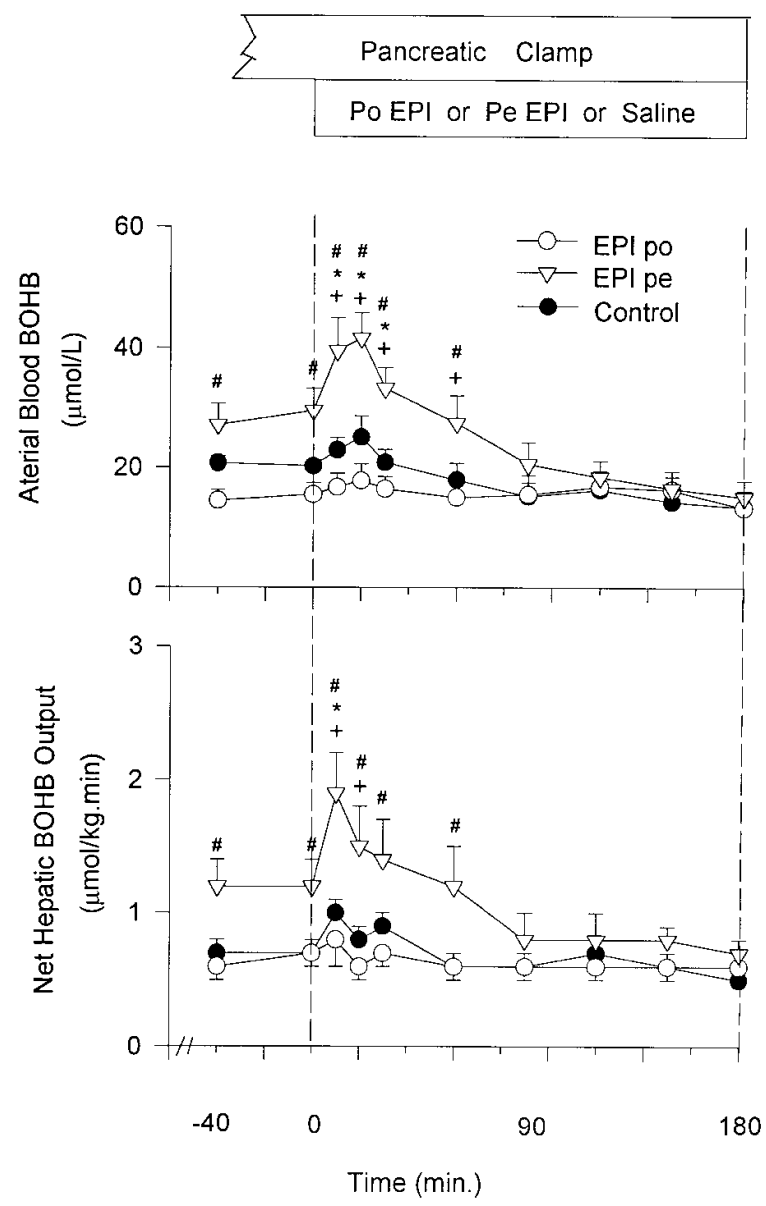

Figure 11. Arterial blood BOHB and net hepatic output during the basal and experimental periods in the presence of a pancreatic clamp in conscious 18 -h-fasted dogs. Data are means \pm SE. ${ }^{+} P<0.05$ difference between the EPI (pe or po) and control groups. ${ }^{\#} P<0.05$ difference between the EPI pe and EPI po groups. $* P<0.05$ vs. corresponding basal period.

clusion is reached if tracer data are used for the calculation (1.5 \pm 0.3 vs. $0.3 \pm 0.1 \mathrm{mg} / \mathrm{kg} \cdot \mathrm{min}, P<0.05)$ (Fig. 14). The contribution of gluconeogenesis to the overall increase in glucose production induced by peripherally delivered epinephrine was marked $(\approx 60 \%$; Fig. 14$)$.

\section{Discussion}

The overall aim of our study was to further characterize the effect of a physiologically relevant increase in epinephrine on hepatic glucose production. Since the arterial and portal levels of insulin and glucagon were clamped at basal values in all groups, since the plasma levels of norepinephrine and cortisol (data not shown) did not change, and since the arterial glucose levels in all groups were similar, we were able to separate the effects of epinephrine on the liver and extrahepatic tissues (muscle and adipose tissue). A 10-fold increase in the hepatic sinusoidal epinephrine level was evident in both groups, but in one case it was accompanied by a 10-fold rise in the arterial epinephrine level and in the other case there was no change in arterial epinephrine. Our data indicate that $\sim 60 \%$ of the ef- 
Table II. Arterial Blood Levels and Net Hepatic Balances of Glutamate, Glutamine, Glycine, Serine, and Threonine during the Basal and Saline versus Portal or Peripheral Epinephrine Infusion Periods in the Presence of a Pancreatic Clamp in Conscious 18-h-fasted Dogs

\begin{tabular}{|c|c|c|c|c|}
\hline \multirow[b]{3}{*}{ Time (min) } & \multicolumn{2}{|c|}{ Arterial blood amino acid level ( $\mu \mathrm{mol} /$ /iter $)$} & \multicolumn{2}{|c|}{ Net hepatic amino acid balance $(\mu \mathrm{mol} / \mathrm{kg} \cdot \mathrm{min})$} \\
\hline & Basal & $\begin{array}{l}\text { Saline versus portal } \\
\text { or peripheral epinephrine }\end{array}$ & Basal & $\begin{array}{l}\text { Saline versus portal } \\
\text { or peripheral epinephrine }\end{array}$ \\
\hline & $-40-0$ & $0-180$ & $-40-0$ & $0-180$ \\
\hline \multicolumn{5}{|l|}{ Glutamate } \\
\hline Control & $196 \pm 54$ & $188 \pm 53$ & $-0.04 \pm 0.07$ & $-0.04 \pm 0.15$ \\
\hline EPI po & $157 \pm 50$ & $156 \pm 53$ & $0.06 \pm 0.09$ & $0.01 \pm 0.08$ \\
\hline EPI pe & $173 \pm 45$ & $176 \pm 46$ & $-0.12 \pm 0.07$ & $-0.07 \pm 0.10$ \\
\hline \multicolumn{5}{|l|}{ Glutamine } \\
\hline Control & $897 \pm 86$ & $898 \pm 93$ & $-0.22 \pm 0.42$ & $-0.27 \pm 0.40$ \\
\hline EPI po & $834 \pm 76$ & $797 \pm 86$ & $-0.19 \pm 0.93$ & $-0.26 \pm 0.68$ \\
\hline EPI pe & $968 \pm 104$ & $942 \pm 83$ & $-0.36 \pm 0.37$ & $-0.06 \pm 0.76$ \\
\hline \multicolumn{5}{|l|}{ Glycine } \\
\hline Control & $169 \pm 20$ & $162 \pm 16$ & $-0.79 \pm 0.23$ & $-1.00 \pm 0.23$ \\
\hline EPI po & $183 \pm 23$ & $147 \pm 19$ & $-1.42 \pm 0.37$ & $-1.39 \pm 0.34$ \\
\hline EPI pe & $165 \pm 26$ & $153 \pm 21$ & $-1.19 \pm 0.25$ & $-1.13 \pm 0.41$ \\
\hline \multicolumn{5}{|l|}{ Serine } \\
\hline Control & $125 \pm 18$ & $117 \pm 14$ & $-0.59 \pm 0.21$ & $-0.73 \pm 0.20$ \\
\hline EPI po & $116 \pm 22$ & $97 \pm 17$ & $-0.86 \pm 0.24$ & $-0.85 \pm 0.20$ \\
\hline EPI pe & $115 \pm 17$ & $113 \pm 15$ & $-0.76 \pm 0.23$ & $-0.76 \pm 0.19$ \\
\hline \multicolumn{5}{|l|}{ Threonine } \\
\hline Control & $220 \pm 37$ & $202 \pm 25$ & $-0.43 \pm 0.39$ & $-0.32 \pm 0.38$ \\
\hline EPI po & $201 \pm 31$ & $167 \pm 31$ & $-0.72 \pm 0.32$ & $-0.55 \pm 0.29$ \\
\hline EPI pe & $137 \pm 31$ & $143 \pm 28$ & $-0.39 \pm 0.26$ & $-0.51 \pm 0.39$ \\
\hline
\end{tabular}

Data are means \pm SE.

fect (over $3 \mathrm{~h}$ ) of epinephrine on hepatic glucose production resulted indirectly from its action on muscle and adipose tissue, and the remainder resulted from its direct effect on liver glycogenolysis. Secondly, they demonstrate that the gluconeogenic effects of circulating epinephrine markedly decreased $(60-80 \%)$ its glycogenolytic action on the liver. Lastly, they show that the direct effect of epinephrine on the liver was solely, at least within $3 \mathrm{~h}$, attributable to glycogenolysis.

Portal infusion of epinephrine raised the hepatic sinusoidal epinephrine level from $42 \pm 14$ to $561 \pm 84 \mathrm{pg} / \mathrm{ml}$ assuming confluence of portal and arterial flows at or before the beginning of the sinusoids (33). Glucose production (whether assessed by tracer or arteriovenous different techniques) was increased by $\approx 1.6 \mathrm{mg} / \mathrm{kg} \cdot \mathrm{min}(10 \mathrm{~min})$. The efficient clearance of epinephrine by the liver $(>95 \%)$ prevented an increase in the arterial epinephrine level $(97 \pm 29$ to $107 \pm 37 \mathrm{pg} / \mathrm{ml})$ which in turn explains the absence of any lipolytic or glycogenolytic effects of epinephrine on adipose tissue or muscle, respectively. As a result there was neither an increase in the delivery of gluconeogenic substrates to the liver nor in the net rates of gluconeogenic precursor ar FFA uptake by the liver. The fact that gluconeogenic precursor uptake did not increase in response to portal epinephrine provides one piece of evidence that epinephrine has little direct gluconeogenic effect on the liver. In fact, neither gluconeogenic efficiency nor the estimated gluconeogenic rate (maximal or minimal) changed within the 3-h observation period. The only hint of a gluconeogenic effect by portal epinephrine was a slight increase in the net hepatic frac- tional extraction of alanine seen at the very end of the study. Since no such effect was seen with any of the other amino acids, it seems unlikely that this effect was of any quantitative significance. Taken together, the above data thus suggest that the increase in glucose production stimulated by portal epinephrine infusion was solely attributable to hepatic glycogenolysis. As such they are consistent with the data from our recent study (6) with a mixture of catecholamines.

Peripheral infusion of epinephrine increased the arterial epinephrine level from $42 \pm 12$ to $1,064 \pm 144 \mathrm{pg} / \mathrm{ml}$ and the hepatic sinusoidal epinephrine level from $20 \pm 8$ to $568 \pm 75 \mathrm{pg} / \mathrm{ml}$. In response to the peripheral epinephrine infusion, hepatic glucose production increased by $\approx 2.9 \mathrm{mg} / \mathrm{kg} \cdot \mathrm{min}(10 \mathrm{~min}) \mathrm{re}$ gardless of whether the arteriovenous difference or tracer methods were used to assess it. The question thus arises as to how much of this increase was attributable to hepatic gluconeogenesis. In response to the peripheral infusion of epinephrine, hepatic gluconeogenic efficiency as well as the maximal and the minimal hepatic gluconeogenic rates were increased from $35 \pm 5$ to $62 \pm 9 \%(P<0.05)$, from $0.7 \pm 0.4$ to $1.8 \pm 0.5 \mathrm{mg} /$ $\mathrm{kg} \cdot \min (P<0.05)$, and $0.3 \pm 0.1$ to $1.1 \pm 0.4 \mathrm{mg} / \mathrm{kg} \cdot \mathrm{min}(P<$ $0.05)$, respectively, within $10 \mathrm{~min}$. Since net hepatic lactate output did not occur, and NHGO did not change (1.4 \pm 0.4 to $1.4 \pm 0.6 \mathrm{mg} / \mathrm{kg} \cdot \mathrm{min}$ at $10 \mathrm{~min})$, subtraction of the initial increase in gluconeogenesis $(1.1$ or $0.8 \mathrm{mg} / \mathrm{kg} \cdot \mathrm{min}$ depending on whether the maximal or minimal estimates of gluconeogenesis were used) from the initial increase in NHGO yields the initial increase in hepatic glycogenolysis $(1.8$ or $2.1 \mathrm{mg} / \mathrm{kg} \cdot \mathrm{min})$. This 


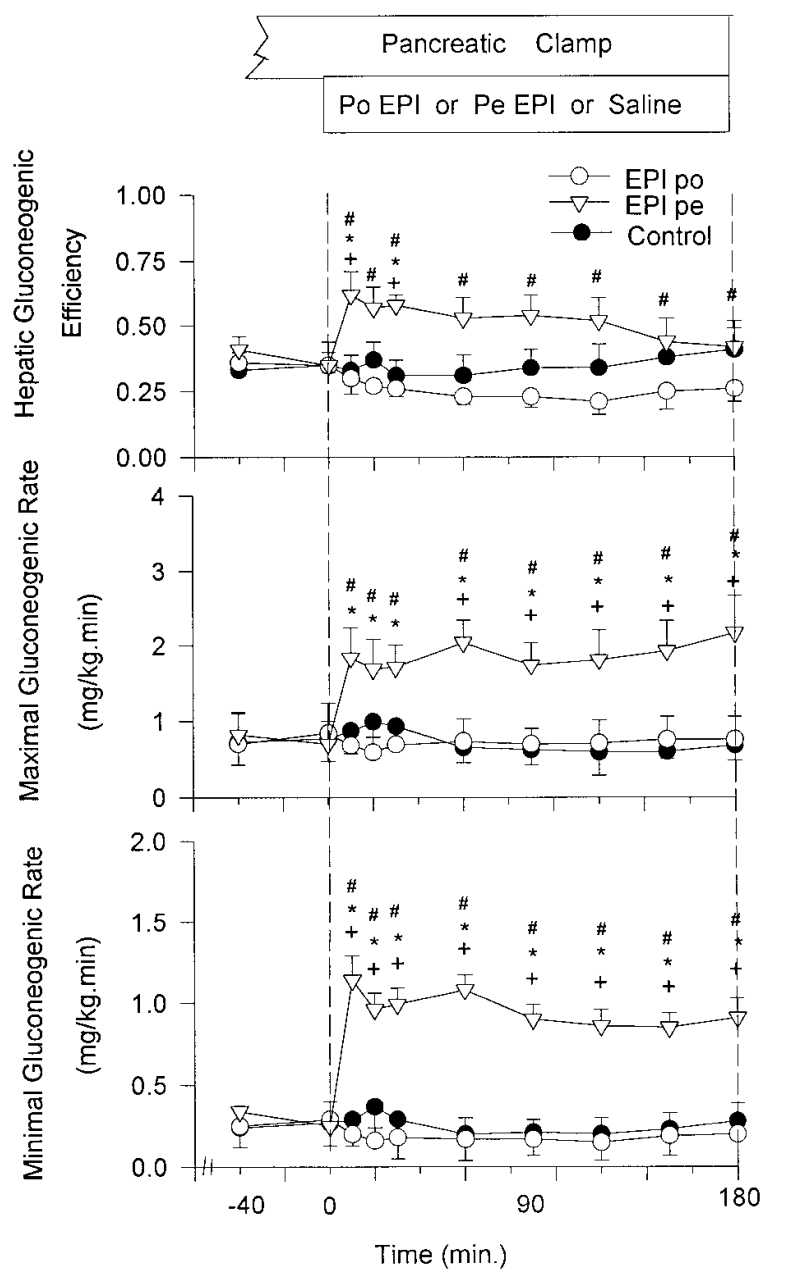

Figure 12. Hepatic gluconeogenic efficiency, maximal, and minimal gluconeogenic rates during the basal and experimental periods in the presence of a pancreatic clamp in conscious 18 -h-fasted dogs. Data are means \pm SE. ${ }^{+} P<0.05$ difference between the EPI (pe or po) and control groups. ${ }^{\#} P<0.05$ difference between the EPI pe and EPI po groups. $* P<0.05$ vs. corresponding basal period.

assumes that the hepatic oxidation rate of glucose $(\approx 10 \%$ of basal glucose production [34]) changed minimally in response to the increase in circulating epinephrine. It is thus apparent that $\sim 30-40 \%$ of the initial increase in glucose production in the EPI pe group arose from the peripheral effects (gluconeogenic precursor supply) of epinephrine. By the end of the study, gluconeogenesis accounted for $\approx 90 \%$ of epinephrine action on glucose production. The present data thus demonstrate that the gluconeogenic effects of epinephrine accounted for $\approx 60 \%$ of its overall effect on hepatic glucose production. To the extent that NHGO reflected total hepatic glucose release in the two EPI groups but underestimated it slightly in the hyperglycemic control group (see Methods), the gluconeogenic contribution to the total hepatic glucose release would be slightly underestimated.

Over the years, it has become evident that the gluconeogenic effects of glucagon are slow to develop (7). Such appears not to be the case with epinephrine. Previously, Sacca et al. (1) showed that in the human the gluconeogenic rate increased by $0.4 \mathrm{mg} / \mathrm{kg} \cdot \mathrm{min}$ within $15 \mathrm{~min}$ of peripheral epinephrine infu-

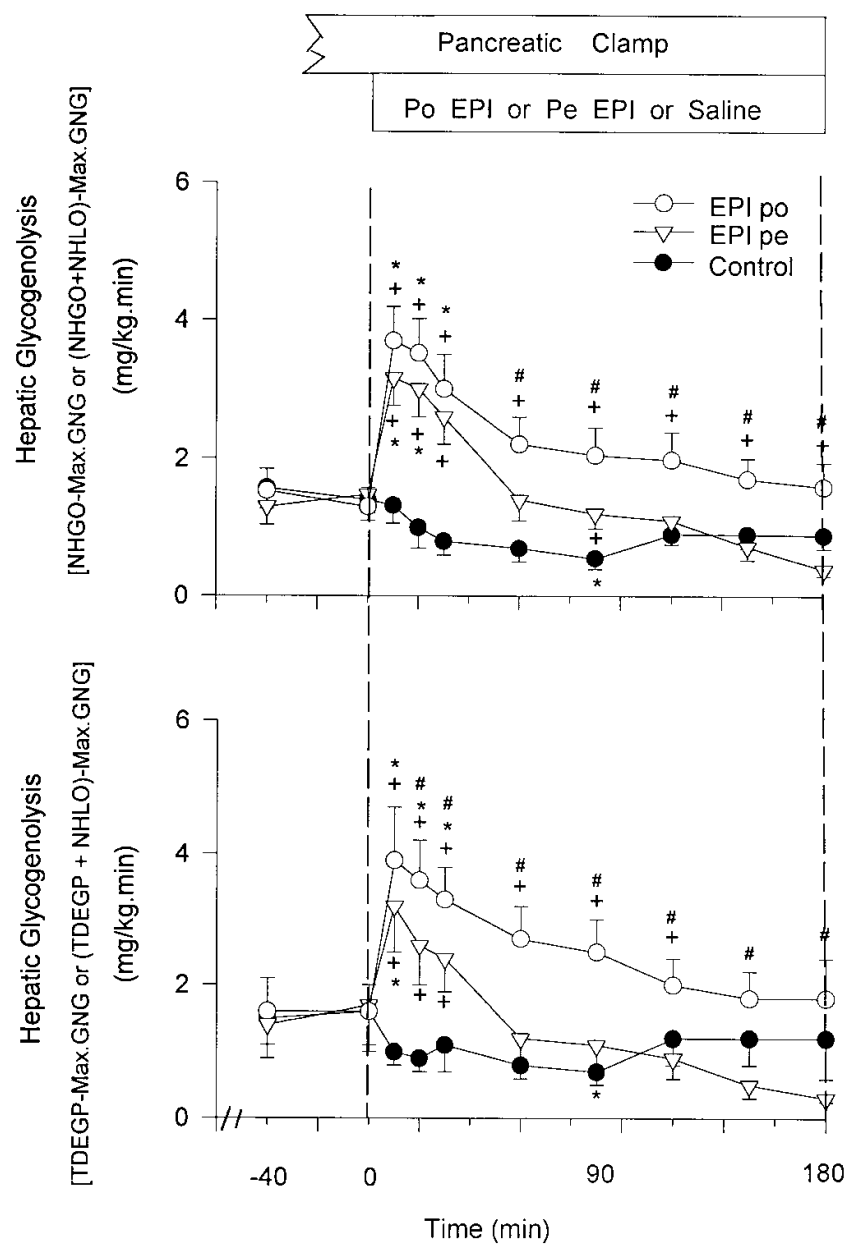

Figure 13. Hepatic glycogenolysis determined by both [NHGO Max.GNG or (NHGO + NHLO) - Max.GNG] and [TDEGP Max. GNG or (TDEGP + NHLO) - Max.GNG] during the basal and experimental periods in the presence of a pancreatic clamp in conscious 18 -h-fasted dogs. Data are means \pm SE. ${ }^{+} P<0.05$ difference between the EPI (pe or po) and control groups. ${ }^{\sharp} P<0.05$ difference between the EPI pe and EPI po groups. ${ }^{*} P<0.05$ vs. corresponding basal period.

sion (60 ng/kg.min). Furthermore, a study by Connolly et al. (35) and our recent study (6) showed that gluconeogenic efficiency and the net hepatic uptakes of major gluconeogenic precursors, such as alanine, lactate, and glycerol, were significantly increased within 10 min of a peripheral catecholamine infusion. The effects of epinephrine on muscle and fat occur quickly such that the gluconeogenic precursor levels in the blood rise rapidly, thereby increasing gluconeogenic precursor uptake by the liver within minutes. The failure of glucagon to rapidly increase gluconeogenesis is probably explained by the fact that it does not increase the gluconeogenic precursor load to the liver in a significant manner.

Given the rapid increase in hepatic gluconeogenesis seen in response to the increment in arterial epinephrine, the question arises as to whether the glycogenolytic action of the hormone on the liver is reduced in the presence of its effects on muscle and adipose tissue. Previous studies (8-11) have shown that a rise in the supply of gluconeogenic precursors reaching the 

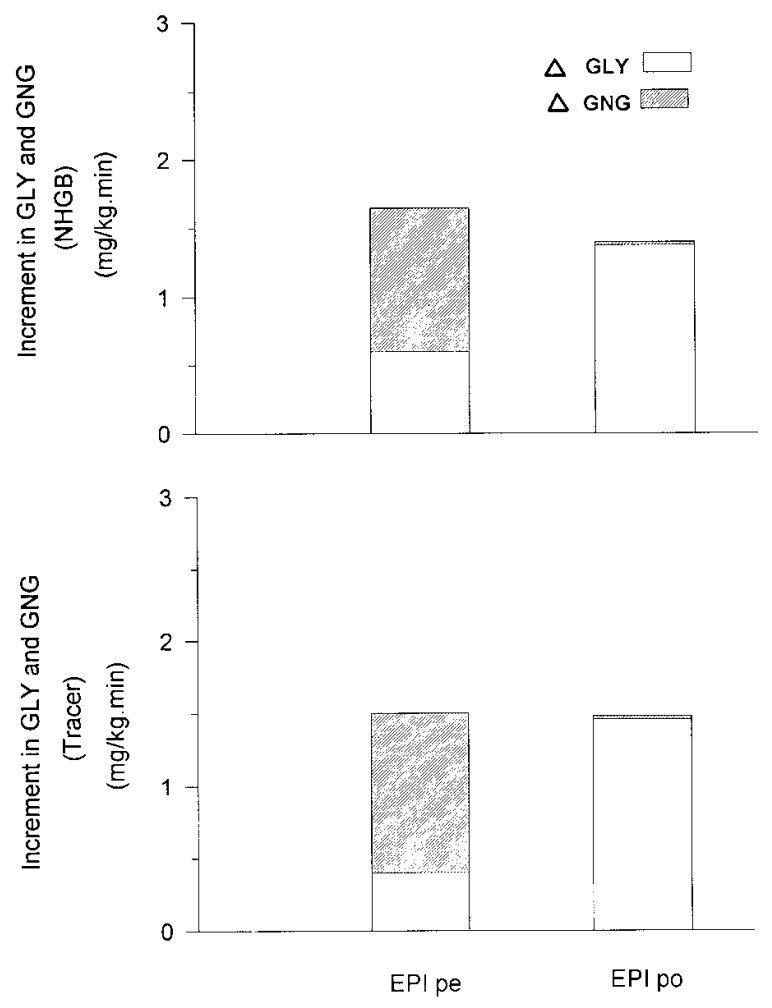

Figure 14. The increment in hepatic gluconeogenesis and glycogenolysis determined by both $[N H G O-M a x . G N G$ or $(N H G O+N H L O)$ - Max.GNG] and [TDEGP - Max.GNG or (TDEGP + NHLO) $M a x . G N G]$ during the experimental period in the presence of a pancreatic clamp in conscious 18 -h-fasted dogs.

liver can increase gluconeogenesis without changing total glucose production. This suggests that a decrease in glycogenolysis is associated with an increase in gluconeogenesis, which in turn implies that hepatic glycogenolysis and gluconeogenesis are reciprocally regulated. In this study, portal infusion of epinephrine initially increased NHGO by $1.7 \mathrm{mg} / \mathrm{kg} \cdot \mathrm{min}(10 \mathrm{~min})$. However, since it also increased the net hepatic lactate output by $7.6 \mu \mathrm{mol} / \mathrm{kg} \cdot \mathrm{min}$ (equal to $0.7 \mathrm{mg} / \mathrm{kg} \cdot \mathrm{min}$ of glucose production), the increase in glucose production underestimates the increase in hepatic glycogenolysis. If the initial increases in the net glucose output and net hepatic lactate output are both taken into account, the increase in hepatic glycogenolysis can be estimated to be $2.4 \mathrm{mg} / \mathrm{kg} \cdot \mathrm{min}$. That glycogen is the net source of the increase in carbon export is evident from the fact that the rate of gluconeogenic precursor uptake by the liver did not change in response to portal epinephrine. It should be noted that since hepatic glucose oxidation accounts for consumption of $\approx 10 \%$ of basal glycogenolysis in the liver of 18 -hfasted dogs (34), a modest change in hepatic glucose oxidation resulting from epinephrine administration would have little, if any, impact on our estimation of the increase in hepatic glycogenolysis. As noted previously, peripheral infusion of epinephrine increased hepatic glycogenolysis by $1.8-2.1 \mathrm{mg} / \mathrm{kg} \cdot \mathrm{min}$. Thus, the initial increase $(10 \mathrm{~min})$ in hepatic glycogenolysis was $13-25 \%$ lower in the EPI pe group than in the EPI po group, even though the hepatic sinusoidal epinephrine levels were indistinguishable. Therefore, these data suggest that the initial increase in gluconeogenesis caused by epinephrine may, to some extent, limit its initial glycogenolytic action on the liver. The overall glycogenolytic effect of epinephrine on the liver in the EPI po and EPI pe groups can be estimated by subtraction of the glycogenolytic rate in the control group from the glycogenolytic rates in the other two groups. In the presence of its effects on gluconeogenic precursor supply the overall effect of epinephrine on liver glycogenolysis was reduced by $60-80 \%$ depending on whether the A-V balance technique or tracer data were used for calculation (Figs. 13 and 14). As noted earlier (see Methods), the use of NHGO is more appropriate than TDEGP to calculate hepatic glycogenolysis, but in the hyperglycemic control group the former probably resulted in a slight underestimate $(\approx 0.4 \mathrm{mg} / \mathrm{kg} \cdot \mathrm{min})$ of the process. This would mean that, if anything, we may have slightly underestimated the inhibitory effect of the increase in the gluconeogenic precursor supply on the glycogenolytic effect of epinephrine. Nevertheless, this inhibitory action would help to explain why a maximally effective level of glucagon has a much greater glycogenolytic effect than a maximally effective level of epinephrine even though they both stimulate hepatic glycogenolysis through the cAMP signaling pathway (36). The latter hormone brings about a significant gluconeogenic response which markedly inhibits its direct action on glycogenolysis, while the former does not because of its inability to mobilize gluconeogenic substrates from peripheral tissues.

NHGO in the EPI pe group fell back to $2.6 \mathrm{mg} / \mathrm{kg} \cdot \mathrm{min}$ by the end of study despite sustained increases in the gluconeogenic rate. It is thus apparent that the glycogenolytic effect of epinephrine on the liver decreased with time. This, of course, relates in part to the progressive increase in gluconeogenesis discussed above. However, since in EPI po group endogenous glucose production also fell in the absence of a change in the gluconeogenic rate, it would appear that the effect of epinephrine on hepatic glycogenolysis is transient for additional reasons. One such reason is the hyperglycemia which occurred (4). Indeed, if one examines the data in the control group, it becomes evident that hyperglycemia per se reduced basal glucose production in the absence of a change in gluconeogenesis indicating a decrease in glycogenolysis. Comparison of the control and EPI po data indicates that hyperglycemia can only partially explain the diminution of hepatic glucose production seen during epinephrine infusion. An additional explanation is provided by the possibility that an intracellular inhibitory signal is generated which shuts down glycogenolysis. It has been known for some time that both glucagon and epinephrine bring about their action on the canine liver via cAMP (36). A previous in vitro study (37) showed that elevation of cAMP and the activation of protein kinase by the hormones induce a negative feedback signal which reduces the cellular cAMP level, thereby minimizing the response of the liver to either hormone.

Recently, Stumvoll et al. (38) reported that a rise in arterial epinephrine can increase tracer-determined renal glucose production in the human. Since no arterial epinephrine increase was seen during portal epinephrine infusion, a renal action would not have affected the response in the EPI po group. Arterial epinephrine increased 10 -fold in response to peripheral infusion, however, raising the question of whether the kidneys might be involved in the increase in tracer-determined glucose production. Since NHGO was indistinguishable from hepatic glucose release in this study during epinephrine infusion (see Methods), and since NHGO paralleled and almost equaled the 
change in tracer-determined glucose production in the EPI pe group, it is apparent that the majority, if not all, of the increase in glucose production must have been attributable to an effect of epinephrine on the liver.

In this study, hepatic gluconeogenic efficiency increased from $35 \pm 5$ to $62 \pm 9 \%(P<0.05)$ in response to the peripheral infusion of epinephrine (Fig. 12). A similar observation was reported by Stevenson et al. (4). Since neither a rise in the hepatic sinusoidal level of epinephrine per se (Fig. 12) nor an increase in the gluconeogenic precursor load reaching the liver alters hepatic gluconeogenic efficiency $(6,11)$, the question arises as to why the increase occurred. It has been shown in vitro that perfusion of the liver with FFA increases gluconeogenesis (39). Recently, Clore et al. (40) found that increasing FFA availability increased gluconeogenesis and glucose production in the human. In addition, Puhakainen et al. (41) showed that decreasing FFA availability reduced gluconeogenesis and glucose production. In this study, arterial FFA, net hepatic FFA uptake, and net hepatic fractional FFA extraction increased from $903 \pm 126$ to $1,611 \pm 139 \mu \mathrm{mol} /$ liter $(P<0.05)$, from $3.5 \pm 0.6$ to $7.8 \pm 1.0 \mu \mathrm{mol} / \mathrm{kg} \cdot \min (P<0.05)$, and by $50 \%$, respectively, in response to the rise in circulating epinephrine (Fig. 10). As such, our data suggest that FFA may be the key to increasing gluconeogenic efficiency in response to epinephrine. The possible mechanisms by which an increase in FFA oxidation within the liver could stimulate gluconeogenic efficiency are $(a)$ production of additional ATP for the support of gluconeogenesis; $(b)$ increasing the availability of the NADH needed for the glyceraldehyde-3-phosphate dehydrogenase reaction; and $(c)$ activating pyruvate carboxylase via an increase in acetyl CoA and other thioesters.

In conclusion, (a) the gluconeogenic effects of circulating epinephrine play the predominant role in its effects on overall hepatic glucose production; $(b)$ the gluconeogenic effects of epinephrine modestly decrease its initial glycogenolytic action on the liver but completely abolish this effect with $90 \mathrm{~min}$; and (c) an increase in hepatic sinusoidal epinephrine per se (for $3 \mathrm{~h}$ ) has no significant effect on hepatic gluconeogenesis.

\section{Acknowledgments}

We are grateful to Dr. David Wasserman, Dr. Mary Genie Moore, Dr. Masakazu Shiota, and Maya Emshwiller for their valuable comments and careful review of this manuscript. We especially appreciate assistance from Jon Hastings, Melanie Scott, Tricia Jackson, Tommy Monohan, Maya Emshwiller, Pam Venson, Wanda Snead, Paul Flakoll, and Annapurna Venkatakrishnan.

This research was supported in part by National Institute of Diabetes and Digestive and Kidney Diseases grants 2RO1 DK-18243 and 5P60 DK-20593 (Diabetes Research and Training Center).

\section{References}

1. Sacca, L., C. Vigorito, M. Cicala, G. Corso, and R.S. Sherwin. 1983. Role of gluconeogenesis in epinephrine-stimulated hepatic glucose production in humans. Am. J. Physiol. 245:E294-E302.

2. Miles, J.M., S.L. Nissen, J.E. Gerich, and M.W. Haymond. 1984. Effects of epinephrine infusion on leucine and alanine kinetics in human. Am. J. Physiol. 247:E166-E172.

3. Clutter, W.E., D.M. Bier, S.D. Shah, and P.E. Cryer. 1980. Epinephrine plasma metabolic clearance rates and physiologic thresholds for metabolic and hemodynamic actions in human. J. Clin. Invest. 66:94-101.

4. Stevenson, R.W., K.E. Steiner, C.C. Connolly, H. Fuchs, K. George, M.M. Alberti, P.E. Williams, and A.D. Cherrington. 1991. Dose-related effects of epinephrine on glucose production in conscious dogs. Am. J. Physiol. 260:
E363-E370

5. Steiner, K.E., R.W. Stevenson, B.A. Marshall, and A.D. Cherrington. 1991. The effects of epinephrine on ketogenesis in the dog after a prolonged fast. Metab. Clin. Exp. 40:1057-1062

6. Chu, C.A., D.K. Sindelar, D.W. Neal, and A.D. Cherrington. 1996. Direct effects of catecholamines on hepatic glucose production in conscious dog are due to glycogenolysis. Am. J. Physiol. 271:E127-E136.

7. Steveson, R.W., K.E. Steiner, M.A. Davis, and A.D. Cherrington. 1987. Similar dose responsiveness of hepatic glycogenolysis and gluconeogenesis to glucagon in vivo. Diabetes. 36:382-389.

8. Wolfe, R.R., F. Jahoor, and J.H.F. Shaw. 1987. Effect of alanine infusion on glucose and urea production in man JPEN (J. Parenter. Enteral. Nutr.). 11: 109-111.

9. Jahoor, F., E.J. Peters, and R.R. Wolfe. 1990. The relationship between gluconeogenic substrate supply and glucose production in humans. Am. J. Physiol. 258:E288-E296.

10. Diamond, M.P., R.C. Rollings, K.E. Steiner, P.E. Williams, W.W. Lacy, and A.D. Cherrington. 1988. Effect of alanine concentration independent of changes in insulin and glucagon on alanine and glucose homeostasis in the conscious dog. Metab. Clin. Exp. 37:28-33.

11. Connolly, C.C., R.W. Stevenson, D.W. Neal, D.H. Wasserman, and A.D. Cherrington. 1993. The effects of lactate loading on alanine and glucose metabolism in the conscious dog. Metab. Clin. Exp. 42:54-161.

12. McGuinness, O.P., T. Fujiwara, S. Murrell, D. Bracy, D.W. Neal, D. O'Connor, and A.D. Cherrington. 1993. Impact of chronic stress hormone infusion on hepatic carbohydrate metabolism in the conscious dog. Am. J. Physiol. 265:E314-E322.

13. Myers, S.R., O.P. McGuinness, D.W. Neal, and A.D. Cherrington. 1991. Intraportal glucose delivery alters the relationship between net hepatic glucose uptake and the insulin concentration. J. Clin. Invest. 87:930-939.

14. Goresky, C.A., C.G. Bach, and B.E. Nadeau. 1975. Red cell carriage of label: its limiting effect on the exchange of material in the liver. Circ. Res. 36: 328-351.

15. Cherrington, A.D., W.W. Lacy, and J.L. Chiasson. 1978. The effect of glucagon on glucose production during insulin deficiency in the dog. J. Clin. Invest. 62:664-667.

16. Wasserman, D.H., R.J. Geer, P.E. Williams, D.B. Lacy, and N.N. Abumard. 1991. Interaction of gut and liver in nitrogen metabolism during exercise. Metab. Clin. Exp. 40:307-314.

17. Lloyd, B., J. Burrin, P. Smythe, and K.G.M.M. Alberti. 1978. Enzymatic fluorometric continuous-flow assays for blood glucose, lactate, pyruvate, alanine, glycerol, and 3-hydroxybutyrate. Clin. Chem. 24:1724-1729.

18. Venkatakrishnan, A., M.J. Abel, R.A. Campbell, E.P. Donahue, T.C. Uselton, and P.J. Flakoll. 1996. Whole blood analysis of gluconeogenic amino acids for estimation of de novo gluconeogenesis using pre-column $o$-phthalaldehyde derivatization and high-performance liquid chromatography. J. Chromatogr. B. Biomed. Appl. 676:1-6

19. Chiasson, J.L., J.E. Lilejenquist, W.W. Lacy, A.S. Jennings, and A.D Cherrington. 1977. Gluconeogenesis: methodological approaches in vivo. Fed. Proc. 36:229-235.

20. Leevy, C.M., C.L. Mendenhall, W. Lesko, and M.M. Howard. 1962. Estimation of hepatic blood flow with indocyanine green. J. Clin. Invest. 41:11691179.

21. Morgan, C.R., and A.L. Lazarow. 1963. Immunoassay of insulin: two antibody system. Plasma insulin of normal, subdiabetic, and diabetic rats. Am. J. Med. Sci. 257:415-419.

22. Moghimzadeh, E., A. Nobin, and E. Rosengren. 1983. Fluorescence microscopical and chemical characterization of the adrenergic innervation in mammalian liver tissue. Cell Tissue Res. 230:605-615.

23. Ishida, T., R.M. Lewis, C.J. Hartley, M.L. Entman, and J.B. Field. 1978. Comparison of hepatic extraction of insulin and glucagon in conscious dogs. Endocrinology. 112:1098-1109.

24. Pagliassotti, M.J., L.C. Holste, M.C. Moore, D.W. Neal, and A.D. Cherrington. 1996. Comparison of the time courses of insulin and the portal signal on hepatic glucose and glycogen metabolism in the conscious dog. J. Clin. Invest. 97:81-91

25. Wall, R.D., R. Steele, R.C. DeBodo, and N. Altszuler. 1957. Effect of insulin on utilization and production of circulating glucose. Am. J. Physiol. 189: $43-50$.

26. DeBodo, R.C., R. Steele, N. Alrszuler, A. Dunn, and J.S. Bishop. 1963 On the hormonal regulation of carbohydrate metabolism: studies with $14 \mathrm{C}$-glucose. Recent Prog. Horm. Res. 19:445-448.

27. Mari, A. 1992. Estimation of the rate of appearance in the non-steady state with a two-compartment model. Am. J. Physiol. 263:E400-E415.

28. Dobbins, R.L., S.N. Davis, D.W. Neal, C. Cobelli, and A.D. Cherrington. 1994. Pulsatility does not alter the response to a physiological increment in glucagon in the conscious dog. Am. J. Physiol. 266:E467-E478.

29. Meyer, C., M. Stumvoll, U. Chintalapudl, O. Gutierrez, M. Kreider, G. Perriello, S. Welle, and J. Gerich. 1996. Alanine and glutamine: selective markers for hepatic and renal gluconeogenesis in humans. Diabetes. 45(Suppl. 1): 945.

30. Wahren, J., P. Felig, G. Ahlborg, and L. Jorfelde. 1971. Glucose metab- 
olism during exercise in man. J. Clin. Invest. 50:2713-2725.

31. Goldstein, R., B. Palmer, R. Liu, and D. Massillon. 1995. The effects of chronic hypercortisolemia on gluconeogenesis assessed using two independent methods in vivo. Diabetes. 44(Suppl. 1):201

32. Giaccari, A., and L. Rossetti. 1992. Predominant role of gluconeogenesis in the hepatic glycogen repletion of diabetes rats. J. Clin. Invest. 89:36-45.

33. Watanabe, Y., G.P. Puschel, A. Gardemann, and K. Jungermann. 1994. Presinusoidal and proximal intrasinusoidal confluence of hepatic artery and portal vein in rat liver: functional evidence by orthograde and retrograde bivascular perfusion. Hepatology. 19:1198-1207.

34. Hamilton, K.S., F.K. Gibbons, D.P. Bracy, D.B. Lacy, A.D. Cherrington, and D.H. Wasserman. 1996. Effect of prior exercise on the partitioning of an intestinal glucose load between splanchnic bed and skeletal muscle. $J$. Clin. Invest. 98:125-135.

35. Connolly, C.C., K.E. Steiner, R.W. Stevenson, D.W. Neal, P.E. Williams, K.G.M.M. Alberti, and A.D. Cherrington. 1991. Regulation of glucose metabolism by norepinephrine in conscious dogs. Am. J. Physiol. 261:E764E772.
36. Exton, L.H. 1987. Mechanisms of hormonal regulation of hepatic glucose metabolism. Diabetes/Metabolism Reviews. 3:163-183.

37. Corbin, J.D., S.J. Beebe, and P.F. Blackmore. 1985. cAMP-dependent protein kinase activation lowers hepatocyte. J. Biol. Chem. 260:8731-8735.

38. Stumvoll, M., U. Chintalapudi, G. Perriello, S. Welle, O. Gutierrez, and J. Gerich. 1995. Uptake and release of glucose by the human kidney. J. Clin. Invest. 96:2528-2533.

39. Williamson, J.R., R.A. Kreisberg, and P.W. Felts. 1966. Mechanism for the stimulation of gluconeogenesis by fatty acids in perfused rat liver. Proc. Natl. Acad. Sci. USA. 56:247-254.

40. Clore, J.N., P.S. Glickman, J.E. Nestler, and W.G. Blackard. 1991. In vivo evidence for hepatic autoregulation during FFA-stimulated gluconeogenesis in normal man. Am. J. Physiol. 261:E425-E429.

41. Puhakainen, I., and H. Yki-jarvinen. 1993. Inhibition of lipolysis decreases lipid oxidation and gluconeogenesis from lactate but not fasting hyperglycemia or total hepatic glucose production in NIDDM. Diabetes. 42:16941699. 